\begin{tabular}{|c|l|}
\hline Title & $\begin{array}{l}\text { Preparation, characterization and photocatalytic performance of titania particles encapsulated in hollow silica shells as } \\
\text { an efficient photocatalyst for redox-combined stereoselective synthesis of L-pipecolinic acid from L-lysine }\end{array}$ \\
\hline Author(s) & Chandren, Sheela; Ohtani, Bunsho \\
\hline Citation & $\begin{array}{l}\text { Journal of Photochemistry and Photobiology A: Chemistry, 246, 50-59 } \\
\text { https:/doi.org/10.1016/.jphotochem.2012.07.007 }\end{array}$ \\
\hline Issue Date & 2012-10-15 \\
\hline Doc URL & http://hdl.handle.net/2115/50408 \\
\hline Type & article (author version) \\
\hline File Information & JPPA 246_50-59.pdf \\
\hline
\end{tabular}

Instructions for use 


\title{
Preparation, characterization and photocatalytic performance of titania particles encapsulated in hollow silica shells as an efficient photocatalyst for redox-combined stereoselective synthesis of $L$-pipecolinic acid from
}

\section{L-lysine}

Sheela Chandren ${ }^{1,2}$ and Bunsho Ohtani ${ }^{1}$

${ }^{1}$ Catalysis Research Center, Hokkaido University, Sapporo 001-0021, Japan

${ }^{2}$ Asian Graduate School of Chemistry and Material Science (Graduate School of Engineering), Hokkaido University, Sapporo 060-8628, Japan

\begin{abstract}
Hollow core-shell particles of a titania core and a silica shell, the latter of which was highly porous, water-swollen and not directly connected to the former, were synthesized by a multistep process including carbon and silica coatings followed by calcination of the carbon-layer combustion. The core-shell particles suspended in aqueous solutions of L-lysine showed improved stereoselectivity in photocatalytic redox-combined synthesis of L-pipecolinic acid (L-PCA), maintaining L-lysine conversion and PCA selectivity, compared with that by bare titania particles, presumably due to the acidic microenvironment of the titania core to control the position of oxidation by positive holes as the first step of the redox-combined process. Modification of the silica layers to acidify them was also beneficial for improvement of optical purity of the product, PCA.
\end{abstract}

Keywords: hollow core-shell particle; titania core; silica shell; photocatalytic synthesis of L-pipecolinic acid; stereoselectivity

\section{Introduction}

Much interest has been shown in photocatalytic reactions occurring on the surface of 
photoirradiated titania $\left(\mathrm{TiO}_{2}\right)$ due to the potential environmental applications [1,2]. An example of such applications is photoinduced decomposition, mineralization, of harmful chemical contaminants in both outdoor and indoor atmospheres. It is believed that this is made possible by the ability of a $\mathrm{TiO}_{2}$ photocatalyst to cleave chemical bonds non-selectively for mineralizing organic compounds under atmospheric conditions, where molecular oxygen $\left(\mathrm{O}_{2}\right)$ in air participates in the photocatalytic reaction to accept photoexcited electrons and to accelerate radical chain oxidation of organic compounds. Despite that, a selective reaction of a targeted chemical, an organic synthesis, is also another extension of $\mathrm{TiO}_{2}$ photocatalysis. Although it has often been misunderstood that $\mathrm{TiO}_{2}$ photocatalysts have oxidation ability that is much greater than that of other metal oxide photocatalysts, the level of the valence band top seems to be not greatly different from those of others and the possible reason for the greater oxidation ability of $\mathrm{TiO}_{2}$ may be its ability for reducing $\mathrm{O}_{2}$. Therefore, one of the most widely used approaches for selective photocatalytic synthesis is operation of a photocatalytic reaction under deaerated conditions where excessive oxidation through radical chain reaction with $\mathrm{O}_{2}$ is not included. Under these conditions, an alternative electron acceptor should be used. Proton $\left(\mathrm{H}^{+}\right)$or water is a possible candidate for the electron acceptor and works with the aid of a noble metal co-catalyst [3-8].

Another approach for selective organic synthesis is structural modification of $\mathrm{TiO}_{2}$ photocatalysts: use of photocatalysts of or in defined microstructures. $\mathrm{TiO}_{2}$ particles or isolated titanium oxide species are dispersed onto or into inorganic supports [9-16]. These inorganic supports should possess pore systems and/or high surface areas. It must be preferable for the preparation of such $\mathrm{TiO}_{2}$-included photocatalysts to use a $\mathrm{TiO}_{2}$ photocatalyst with higher activities as a base $\mathrm{TiO}_{2}$ source and modify it adequately, since there seems to be no guarantee to obtain $\mathrm{TiO}_{2}$-included photocatalysts with high photocatalytic activity when they are prepared using a titanium compound(s) as a $\mathrm{TiO}_{2}$ source. Therefore, commercially available $\mathrm{TiO}_{2}$ particles with reported sufficiently high activity are preferable compared with those synthesized in situ or ex situ. According to previous works [17-20], one of the most widely used methods to provide commercial $\mathrm{TiO}_{2}$-selective 
photocatalytic functions is encapsulation of $\mathrm{TiO}_{2}$ particles into porous substances. Due to the surface coverage of these substances, however, the composites obtained through this approach have a tendency to decrease intrinsic photocatalytic activity of the medial $\mathrm{TiO}_{2}$. On the other hand, we have recently reported [21,22] the fabrication of a novel core-shell composite photocatalyst that consists of commercially available $\mathrm{TiO}_{2}$ particles incorporated in a hollow silica shell $\left(\mathrm{SiO}_{2} /\right.$ void/TiO $\left.{ }_{2}\right)$. The composite hollow core-shell particles possessed size-selective properties in the photodecomposition of organic compounds; $\mathrm{SiO}_{2} /$ void/TiO showed photocatalytic activity for decomposition of small substrates such as acetic acid while retaining the activity of original bare $\mathrm{TiO}_{2}$, whereas negligible activity for polymers such as poly(vinyl alcohol) was observed; i.e., $\mathrm{SiO}_{2} /$ void $/ \mathrm{TiO}_{2}$ exhibited molecular size selectivity $[23,24]$.

Pipecolinic acid (PCA) is one of the most important intermediate compounds for the syntheses of a wide range of medicines and/or biologically active chemical compounds [25]; for example, a commercially available local anesthetic, L- $N$-propylpipecolinic acid 2,6xylidide, is synthesized from L-(S)-PCA (L-PCA) [26]. The fact that the starting material is optically pure, cheap and readily available makes the deaminocyclization of L-(S)-lysine (L-Lys) a preferable chemistry process to obtain L-PCA [27]. In addition, only ammonia is released as a by-product in the reaction using L-Lys as a source. Excellent examples of a photocatalytic one-step synthesis of L-PCA from L-Lys in which deaerated aqueous solutions of L-Lys with suspended particulate semiconductor photocatalysts $\left(\mathrm{TiO}_{2}\right.$ or cadmium sulfide (CdS)) were subjected to photoirradiation have been reported [27-29]. The photocatalytic synthesis proceeds under atmospheric pressure at room temperature without the need to protect functional groups in L-Lys. The proposed mechanism of the above-mentioned photocatalytic deaminocyclization of L-Lys involves successive oxidation of one of the amino groups in L-Lys into imines by two positive holes $\left(h^{+} \mathrm{s}\right)$, hydrolysis of the imines into aldehyde or ketone, intramolecular condensation of them with the remaining amino group into a cyclic Schiff base (CSB), and reduction of CSB into PCA by two photoexcited electrons $\left(e^{-} \mathrm{s}\right)[27,28]$, as shown in Scheme 1. Such a combination of reduction and oxidation is one 
of the characteristic features of photocatalytic PCA synthesis, since equimolar oxidation and reduction by $h^{+}$and $e^{-}$, respectively, proceed separately in ordinary photocatalytic reaction systems, giving different reduction and oxidation products. Since $h^{+}$and $e^{-}$produced in a particle must be consumed on the surface of each particle in the photocatalytic reaction of semiconductor particles, the sites for oxidation and reduction might be located nearby, enabling induction of a redox-combined reaction.

The optical purity of the product PCA $\left(\mathrm{OP}_{\mathrm{PCA}}\right)$ depends on the type of photocatalyst used. $\mathrm{TiO}_{2}$ photocatalysts gave rise to L-excess, while its $\mathrm{CdS}$ counterpart gave almost racemic PCA [28]. This dependence can be attributed to the difference in position of attack by $h^{+}$generated with the photoexcitation of a photocatalyst. This includes factors such as which amino group in L-Lys undergoes preferential oxidative attack by $h^{+}$; as shown in Scheme 1 , oxidation of an $\alpha$-amino group into $\alpha$-keto acid leads to the loss of chirality, whereas oxidation of an $\varepsilon$-amino group has no effect on optical activity. Infrared spectroscopic analyses of the behavior of L-Lys adsorbed on thin-film photocatalysts suggested that $h^{+}$in $\mathrm{CdS}$ can oxidize only the $\alpha$-amino group, while $\mathrm{TiO}_{2}$ oxidizes the $\varepsilon$-amino group predominantly. $\mathrm{A} \mathrm{TiO}_{2}$-based photocatalyst is commonly used to achieve high $\mathrm{OP}_{\mathrm{PCA}}$ in the photocatalytic synthesis of PCA from L-Lys. However, Pal et al. [27] reported that they were not able to obtain optically pure PCA by $\mathrm{TiO}_{2}$ photocatalysis with maintenance of relatively high conversion of L-Lys and selectivity of PCA $\left(\mathrm{S}_{\mathrm{PCA}}\right)$. This is due to the inevitable $\alpha$-amino-group oxidation. Such selectivity of the oxidation position in L-Lys may depend on the micro-environment for photocatalytic reaction, including surface properties of a photocatalyst, as well as the potential of $h^{+}$to oxidize amino groups. Therefore, modification of the surface and/or environment near the surface is a possible strategy for selective photocatalytic reaction with maintenance of a high rate.

In previous reports, the size-selectivity and adsorption effect obtained from a lateral $\mathrm{SiO}_{2}$ shell have been well covered and discussed. Upon further examination of the composite, some remarkable photocatalytic characteristics were discovered, especially those related to the presence of a lateral $\mathrm{SiO}_{2}$ shell, which was briefly reported in our paper 
published recently [30]. In this paper, detailed structural characteristics of this core-shell composite and photocatalytic activity in the synthesis of L-PCA from L-Lys are reported, another function of $\mathrm{SiO}_{2}$ shell, which is to improve molecular selectivity, instead of size selectivity, is reported. In order to study those above-mentioned aspects, the main aim of this study was to fabricate $\mathrm{SiO}_{2} /$ void/TiO 2 composites with various shell thicknesses and also sizes of void spaces via modification of the previously reported procedure. Modifications to the $\mathrm{SiO}_{2}$ shell to control the microenvironment of the $\mathrm{TiO}_{2}$ core are also discussed.

\section{Experimental}

\subsection{Materials}

Commercial anatase $\mathrm{TiO}_{2}$ supplied by Ishihara Sangyo (ST-41) was used mainly in this study. Other commercial chemicals were used without further purification. Laboratory-grade water was prepared using a Millipore pure water system.

\subsection{Fabrication of titania coated with a hollow silica shell $\left(\mathrm{SiO}_{2} /\right.$ void/TiO $\left.{ }_{2}\right)$}

$\mathrm{SiO}_{2} /$ void $/ \mathrm{TiO}_{2}$ was prepared by coating of $\mathrm{TiO}_{2}$ with a carbon layer and then an $\mathrm{SiO}_{2}$ layer followed by heat treatment to remove the carbon layer by its combustion. A $0.2-\mathrm{g}$ portion of $\mathrm{TiO}_{2}$ powder was suspended in a methanolic solution $\left(10 \mathrm{~cm}^{3}\right)$ of 3-aminopropyltrimethoxysilane (APS; $1.1 \mathrm{mmol}$ ). After vigorous stirring of the suspension for $2 \mathrm{~h}$ at room temperature, the sample was washed with ethanol and dried overnight at 353 K. The APS-modified $\mathrm{TiO}_{2}$ was then suspended in $65 \mathrm{~cm}^{3}$ of aqueous glucose with different concentrations $\left(0.25-1.0 \mathrm{~mol} \mathrm{dm}^{-3}\right)$, in order to vary the thickness of the void space, in a rotating Teflon-sealed autoclave at $453 \mathrm{~K}$ for $6 \mathrm{~h}$. Glucose solutions with concentrations of $0.5 \mathrm{~mol} \mathrm{dm}^{-3}$ were used unless stated otherwise. The resulting polysaccharide (PS)-covered particles were filtered, washed with water several times and with ethanol, and heated at $873 \mathrm{~K}$ under vacuum for $2 \mathrm{~h}$. This procedure resulted in coating of the particle aggregates with a thick uniform layer of amorphous carbon $\left(\mathrm{C} / \mathrm{TiO}_{2}\right)$. In the next step, $0.2 \mathrm{~g}$ of the obtained $\mathrm{C} / \mathrm{TiO}_{2}$ was stirred in a methanolic solution $\left(10 \mathrm{~cm}^{3}\right)$ of $0.42 \mathrm{mmol}$ 
n-(2-aminoethyl)-3-aminopropyltrimethoxysilane (AEAPS) for $2 \mathrm{~h}$ at ambient temperature. The resulting AEAPS-treated sample was suspended in methanol $\left(15 \mathrm{~cm}^{3}\right)$ containing 2.2 mmol tetraethyl orthosilicate (TEOS), $0.5 \mathrm{~cm}^{3}$ aqueous ammonia (28\%) and $2 \mathrm{~cm}^{3}$ water and agitated for $0.5-3.0 \mathrm{~h}$ at room temperature. $\mathrm{TiO}_{2}$ particles covered with carbon and $\mathrm{SiO}_{2}$ layers $\left(\mathrm{SiO}_{2} / \mathrm{C} / \mathrm{TiO}_{2}\right)$ were obtained after heat treatment for dehydration polymerization of silicate under vacuum at $873 \mathrm{~K}$. Finally, the carbon layer was removed by calcination at $873 \mathrm{~K}$ for $2 \mathrm{~h}$ in air, thus successfully yielding $\mathrm{TiO}_{2}$ encapsulated in a hollow $\mathrm{SiO}_{2}$ shell $\left(\mathrm{SiO}_{2} /\right.$ void $\left./ \mathrm{TiO}_{2}\right) . \quad \mathrm{SiO}_{2} /$ void $/ \mathrm{TiO}_{2}$ samples obtained after different silylation periods with TEOS were labeled $\mathrm{SiO}_{2}$ (silylation time)/void/TiO 2 (e.g., $\mathrm{SiO}_{2}(0.5) /$ void/TiO ${ }_{2}$ for a sample obtained after agitation with TEOS for $0.5 \mathrm{~h}$ ).

As reference samples for comparison, $\mathrm{TiO}_{2}$ mechanically mixed with $\mathrm{SiO}_{2}\left(m e c-\mathrm{SiO}_{2}+\mathrm{TiO}_{2}\right)$ and $\mathrm{TiO}_{2}$ directly coated with $\mathrm{SiO}_{2}\left(\right.$ dir- $\left.-\mathrm{SiO}_{2} / \mathrm{TiO}_{2}\right)$ were also prepared. In the synthesis of mec-SiO $2+\mathrm{TiO}_{2}, \mathrm{ST}-41 \mathrm{TiO}_{2}$ was mechanically stirred with $\mathrm{SiO}_{2}$ (Wako, ratio of $\mathrm{TiO}_{2}: \mathrm{SiO}_{2}=3: 2$ ) in methanol for $24 \mathrm{~h}$ at room temperature, and then the mixture was calcined at $873 \mathrm{~K}$ for $2 \mathrm{~h}$ in air. The $\operatorname{dir}-\mathrm{SiO}_{2} / \mathrm{TiO}_{2}$ powder was prepared according to the procedures reported by Graf et al. [31] with slight modification. A brief description is as follows: $0.2 \mathrm{~g}$ of $\mathrm{TiO}_{2}$ was suspended in an aqueous solution $\left(18 \mathrm{~cm}^{3}\right)$ of poly(vinylpyrrolidone) (PVP) $\left(2.3 \mathrm{mmol} \mathrm{dm}^{-3}\right)$ and the suspension was stirred for $12 \mathrm{~h}$ at ambient temperature. $\mathrm{PVP}$-adsorbed $\mathrm{TiO}_{2}$ powder was collected and then stirred for $1.5 \mathrm{~h}$ in an ethanolic solution $\left(14 \mathrm{~cm}^{3}\right)$ of $0.5 \mathrm{mmol}$ tetraethyl orthosilicate (TEOS), $0.5 \mathrm{~cm}^{3}$ aqueous ammonia (28\%) and $2 \mathrm{~cm}^{3}$ water. The resulting powder was collected by centrifugation and then washed with water and heated at $873 \mathrm{~K}$ for $2 \mathrm{~h}$ in air.

\subsection{Modifications of particle surfaces with acid sources}

Functionalization of external surfaces of $\mathrm{SiO}_{2} /$ void/ $\mathrm{TiO}_{2}$ with acid was carried out with sulfuric acid $\left(\mathrm{H}_{2} \mathrm{SO}_{4}\right)$ or 3-mercaptopropyl trimethoxysilane (MPTS). For modifications with $\mathrm{H}_{2} \mathrm{SO}_{4}$, treatments were done in the synthesis process of the hollow core-shell particles just before removal of the carbon layer. After obtaining $\mathrm{TiO}_{2}$ particles 
covered with carbon and $\mathrm{SiO}_{2}$ layers $\left(\mathrm{SiO}_{2} / \mathrm{C} / \mathrm{TiO}_{2}\right), 0.2 \mathrm{~g}$ of the sample was agitated in a methanolic solution $\left(10 \mathrm{~cm}^{3}\right)$ containing an equal molar amount of $\mathrm{H}_{2} \mathrm{SO}_{4}$ for $2 \mathrm{~h}$, followed by drying and calcination at $873 \mathrm{~K}$ for $2 \mathrm{~h}$ in air. The sample modified with $\mathrm{H}_{2} \mathrm{SO}_{4}$ is denoted as $\mathrm{SiO}_{2} /$ void $/ \mathrm{TiO}_{2}+\mathrm{H}_{2} \mathrm{SO}_{4}$. For modification with MPTS, treatment was done during the silylation process in $\mathrm{SiO}_{2} /$ void/TiO $/ \mathrm{TiO}_{2}$ synthesis. The AEAPS-treated $\mathrm{C} / \mathrm{TiO}_{2}$ was suspended in a methanolic solution $\left(15 \mathrm{~cm}^{3}\right)$ containing $2.2 \mathrm{mmol}$ TEOS, $0.5 \mathrm{~cm}^{3}$ aqueous ammonia (28\%) and $2 \mathrm{~cm}^{3}$ water and agitated at room temperature. Then an equimolar amount of MPTS was added and the mixture was again shaken for another $2 \mathrm{~h}$. Finally, the carbon layer was removed by calcinations at $873 \mathrm{~K}$ for $2 \mathrm{~h}$ in air. The thus-obtained sample is denoted as $\mathrm{SiO}_{2} /$ void/TiO $2+\mathrm{MPTS}$.

\subsection{Platinization of samples}

Since platinum $(\mathrm{Pt})$ deposits on the $\mathrm{TiO}_{2}$ surface, as a co-catalyst accelerating reduction by photoexcited electrons as discussed in Results and Discussion, are required for the photocatalytic synthesis of L-PCA [32], all samples were platinized (2wt\% to $\left.\mathrm{TiO}_{2}\right)$ using a two-step photodeposition method. First, a sample was suspended in water containing the required amount of hydrogen hexachloroplatinate(IV) $\left(\mathrm{H}_{2} \mathrm{PtCl}_{6} \cdot 6 \mathrm{H}_{2} \mathrm{O}\right)$ and irradiated by a 400-W mercury arc (Eiko-sha 400; ca. $25 \mathrm{~mW} \mathrm{~cm}^{-2}$ at 300-400 nm) for $1.5 \mathrm{~h}$ and then irradiated for an additional $1.5 \mathrm{~h}$ in the presence of $50 \mathrm{vol} \%$ methanol at $298 \pm 0.5 \mathrm{~K}$. The process of Pt deposition was monitored by measuring the amount of hydrogen $\left(\mathrm{H}_{2}\right)$ liberated by the photoirradiation using a gas chromatograph as was used in the photocatalytic reaction described below.

\subsection{Characterization of photocatalyst particles}

Scanning electron microscopic (SEM) images were obtained by a JEOL JSM-7400F microscope equipped with a detector for transmission electron microscopic mode (TED). X-Ray diffraction (XRD) patterns were recorded on a Rigaku SmartLab X-ray diffractometer with $\mathrm{Cu} \mathrm{K} \mathrm{K}_{\alpha}$ radiation. Specific surface area and pore-volume distribution were measured by 
the Brunauer-Emmett-Teller (BET) method using nitrogen adsorption at $77 \mathrm{~K}$ on a Quantachrome Autosorb 6AG/HOB surface area and pore size analyzer. Before surface area and pore volume distribution analyses, sample powders were heated at $473 \mathrm{~K}$ under vacuum for $2 \mathrm{~h}$. Surface acidity was measured by temperature-programmed desorption of ammonia ( $\mathrm{NH}_{3}$-TPD) with a TPD Instrument (BEL JAPAN) equipped with a quadrupole mass spectrometer (M-100QA, ANELVA). Prior to the adsorption of $\mathrm{NH}_{3}$, ca. $100 \mathrm{mg}$ of a sample was heated under a helium (He) environment at $773 \mathrm{~K}$ for $2 \mathrm{~h}$ and then cooled to 373 K. Subsequently, the sample was exposed to an ammonia gas flow for $1 \mathrm{~h}$ and then purged by $\mathrm{He}$ gas for $40 \mathrm{~min}$ to remove excessive physically adsorbed ammonia. All $\mathrm{NH}_{3}$-TPD profiles were obtained by elevating the sample temperature from 373 to $773 \mathrm{~K}$ at a rate of 10 $\mathrm{Kmin}^{-1}$.

\subsection{Photocatalytic reaction}

For the photocatalytic reaction of redox-combined stereoselective synthesis of L-pipecolinic acid (L-PCA) from L-lysine (L-Lys), a Pt-loaded photocatalyst (0.050 g as $\mathrm{TiO}_{2}$ ) was suspended in an aqueous solution $\left(5.0 \mathrm{~cm}^{3}\right)$ containing L-Lys $(100 \mu \mathrm{mol})$ and photoirradiated by a high-pressure mercury arc (Eiko-sha, $400 \mathrm{~W}$ ) under argon (Ar) with magnetic stirring $(1000 \mathrm{rpm})$. The photoirradiation was performed through a cylindrical Pyrex glass filter and a glass reaction tube $(18 \mathrm{~mm}$ in diameter and $180 \mathrm{~mm}$ in length) so that light of wavelength $>290 \mathrm{~nm}$ reached the suspension. The temperature of the suspension during photoirradiation was maintained at $298 \pm 0.5 \mathrm{~K}$ by the use of a thermostated water bath. After irradiation for $2 \mathrm{~h}$, a $0.2-\mathrm{cm}^{3}$ portion of the gas phase of the sample tube was withdrawn with a gas-tight syringe and subjected to gas chromatographic analysis (GC, Shimadzu GC-8A with a molecular sieve 5A column and a TCD detector) for $\mathrm{H}_{2}$ analysis. The yield of enantiomers of PCA, as well as the amount of unreacted L-Lys, was measured by HPLC (Shimadzu LC-6A equipped with a Daicel Chiral-Pak MA(+) column and an ultraviolet absorption detector) as reported previously [27]. 


\section{Results and Discussion}

\subsection{Preparation and characterization of hollow core-shell structured particles}

An SEM image of $\mathrm{TiO}_{2}$ (Ishihara ST-41) as a starting material is shown in Fig. 1(a). A characteristic angular morphology of the sample was distinctly observed, with particle size in the range of $100-300 \mathrm{~nm}$. The $\mathrm{TiO}_{2}$ was then pretreated with a methanolic solution of APS in aqueous glucose at $453 \mathrm{~K}$ and subsequently subjected to hydrothermal treatment. This resulted in the encapsulation of particle aggregates with a thick uniform layer of carbon $\left(\mathrm{C} / \mathrm{TiO}_{2}\right.$, Fig. 1(b)). The thickness of the layer was 30-80 nm, which is in agreement with the results of a previous study showing that glucose undergoes conversion into carbonaceous polysaccharide (PS) spheres by hydrothermal treatment at the temperature range of 433-453K [33]. Stirring the reaction mixture by rotating the autoclave was indispensable for the uniform coating of particles, presumably because the PS formation proceeds spontaneously and PS particles could be obtained in the absence of $\mathrm{TiO}_{2}$ particles. The utilization of certain oxide particles during the hydrothermal reaction of glucose gave rise to a uniform layer of PS on the particles instead of formation of PS spheres [21-24]. Heat treatment at $873 \mathrm{~K}$ under vacuum resulted in conversion of the PS layer to an amorphous carbon layer [22]. Also an important point is the use of APS-treated $\mathrm{TiO}_{2}$; use of bare $\mathrm{TiO}_{2}$ failed to produce surface-covered particles and resulted in the formation of PS spheres. The APS-treated $\mathrm{TiO}_{2}$ might improve preferable adsorption of the PS component via acid-base interactions between carboxyl and amino groups, since the PS component has a substantial amount of the former and the treated $\mathrm{TiO}_{2}$ should have the latter on its surface [23]. Figure 1(c) shows the effect of consecutive treatments on $\mathrm{C} / \mathrm{TiO}_{2}$ with AEAPS and TEOS in ethanol, whereby the coverage of an outer layer of the sample was observed. Another noteworthy observation was the absence of free $\mathrm{SiO}_{2}$ particles. This indicates surface coverage with an $\mathrm{SiO}_{2}$ layer by exclusive progress in a polycondensation reaction at the surface of $\mathrm{C} / \mathrm{TiO}_{2}$. This in turn resulted in the formation of $\mathrm{SiO}_{2} / \mathrm{C} / \mathrm{TiO}_{2}$ composite particles. Heating of the sample in air at $873 \mathrm{~K}$ was subsequently performed to remove carbon components from $\mathrm{SiO}_{2} / \mathrm{C} / \mathrm{TiO}_{2}$ by combustion of carbon. 
Other commercial $\mathrm{TiO}_{2}$ powders such as Evonik (Degussa) P25 were used for the core, but they failed; it seems difficult to obtain a uniform carbon layers on the $\mathrm{TiO}_{2}$ surface in hydrothermal reaction in an aqueous glucose solutions. Although the reason is still unknown, a trial to obtain an $\mathrm{SiO}_{2} /$ void/ $/ \mathrm{TiO}_{2}$-type structure from those $\mathrm{TiO}_{2}$ powders is currently being performed by modifying the surface pretreatment processes.

SEM images of the thus-obtained white powders showed that they are comprised of $\mathrm{TiO}_{2}$ aggregates encapsulated in hollow $\mathrm{SiO}_{2}$ shells (i.e., $\mathrm{SiO}_{2}(1.5) /$ void/ $\mathrm{TiO}_{2}$ ), as shown in Fig. 2(b). Control of the thickness of the lateral $\mathrm{SiO}_{2}$ shell was possible by changing the duration of the $\mathrm{SiO}_{2}$ growth process. Extension of the reaction duration resulted in a thicker $\mathrm{SiO}_{2}$ layer (Fig. 2(c)) and vice versa (Fig 2(a)). Control of the size of the void space was also possible by changing the concentration of aqueous glucose during the carbon coating step. A higher concentration of aqueous glucose resulted in a larger void space (Fig. 3(c); several tens of nanometers) and vice versa (Fig 3(a); ca. $10 \mathrm{~nm}$ ) compared with that of the standard sample (Fig. 3(b)) prepared with glucose solution of $0.5 \mathrm{~mol} \mathrm{dm}^{-3}$ (a few tens of nanometers). These hollow core-shell particles were prepared with a silylation period of $1.5 \mathrm{~h}$, and the $\mathrm{SiO}_{2}$ shell thicknesses therefore were almost the same in those samples.

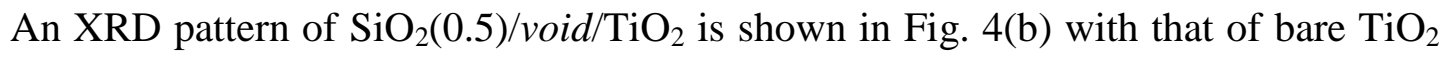
(ST-41) (Fig. 4(a)) for comparison. By comparing these XRD patterns, it was concluded that there was no significant change after the formation of $\mathrm{SiO}_{2} /$ void/ $/ \mathrm{TiO}_{2}$; the preparation process for $\mathrm{SiO}_{2} /$ void/TiO 2 induces negligible change in anatase $\mathrm{TiO}_{2}$ crystal structure. Aside from having the same widths and intensities of all peaks as those of bare ST-41, no extra peaks were observed for $\mathrm{SiO}_{2} /$ void/TiO 2 , indicating an amorphous nature of the lateral $\mathrm{SiO}_{2}$ shells.

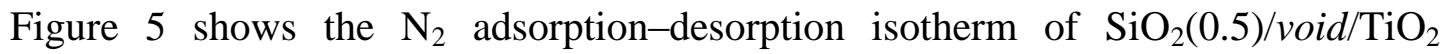
derived from ST-41 and that of bare ST-41. Compared with the isotherm of the bare sample, the isotherm of $\mathrm{SiO}_{2}(0.5) /$ void/ $\mathrm{TiO}_{2}$ showed the presence of a substantial hysteresis loop that is closed by a drop of the desorption branch in the volume adsorbed at $\mathrm{P} / \mathrm{P}_{0}$ of ca. 0.5. This is attributable to the tensile strength effect (TSE), a phenomenon usually observed in samples 
having a porous structure [34], suggesting that the lateral $\mathrm{SiO}_{2}$ shell has a porous structure. A method that is commonly used for $\mathrm{SiO}_{2}$-based microporous materials such as zeolites and $\mathrm{SiO}_{2}$ gels for determination of micropore size distribution is the Saito-Foley (SF) model. In this study, application of the SF model to the adsorption branch resulted in specifying the pore system mainly ranging between $c a .0 .4$ and $1.2 \mathrm{~nm}$. As stated in the literature [35,36], the fabrication of hollow $\mathrm{SiO}_{2}$ spheres involved based-catalyzed hydrolysis and polycondensation of TEOS. After applying similar method in our study, it was observed that $\mathrm{SiO}_{2}$ shells were composed of aggregates of $\mathrm{SiO}_{2}$ nanoparticles. Therefore, the vacant spaces between these aggregates are the reason for the observed microporous structure on $\mathrm{SiO}_{2} /$ void/TiO $2 . \quad$ Such a microporous structure of the lateral $\mathrm{SiO}_{2}$ shell contributed to the successful removal of the medial carbon shell in $\mathrm{SiO}_{2} / \mathrm{C} / \mathrm{TiO}_{2}$. On the other hand, the spaces between the $\mathrm{TiO}_{2}$ core and the $\mathrm{SiO}_{2}$ shell seemed sufficiently large for not being detected in the $\mathrm{N}_{2}$ adsorption measurement.

The presence of void spaces was also supported by the fact that the specific surface area, calculated from the above-mentioned $\mathrm{N}_{2}$ adsorption, of $\mathrm{SiO}_{2} /$ void/TiO $2\left(29 \mathrm{~m}^{2} \mathrm{~g}^{-1}\right)$ was more than two times larger than that of the original $\mathrm{TiO}_{2}\left(13 \mathrm{~m}^{2} \mathrm{~g}^{-1}\right)$.

Figure 6 shows $\mathrm{NH}_{3}$-TPD patterns corresponding to the surface acidity of the original bare ST-41 $\left(\mathrm{TiO}_{2}\right), \mathrm{TiO}_{2}$ that had been modified with APS followed by heating at $873 \mathrm{~K}$ (APS-TiO 2 ) and $\mathrm{TiO}_{2}$ that had been modified with APS followed by carbon coating and then calcination at $873 \mathrm{~K}$ to remove the carbon layer $\left(\mathrm{C}-\mathrm{TiO}_{2}\right)$. The original ST-41 shows some acidic sites, presumably due to the remaining sulfuric acid from the starting material of this $\mathrm{TiO}_{2}$, titanium sulfate. As seen in Fig. 6, the acidity decreased significantly for APS-TiO possibly due to neutralization of those acid sites by the amino groups in APS. A smaller decrease in acidity was observed for $\mathrm{C}-\mathrm{TiO}_{2}$, as compared to the acidity shown by $\mathrm{APS}-\mathrm{TiO}_{2}$. One possible reason is that the carbon coating with calcination removes the amino groups that neutralized the acid sites, thus resulting in recovery of some of the original acid sites, though at present we have no experimental evidence supporting this. 
$\mathrm{NH}_{3}$-TPD patterns for $\operatorname{dir}-\mathrm{SiO}_{2} / \mathrm{TiO}_{2}$, dir- $\mathrm{SiO}_{2} / \mathrm{TiO}_{2}$ heated at $973 \mathrm{~K}$, which is slightly higher than the temperature for $\mathrm{SiO}_{2}(1.5) /$ void/TiO 2 preparation $(873 \mathrm{~K})$, and $\mathrm{SiO}_{2}(1.5) /$ void/TiO 2 are shown in Fig. 7. $\mathrm{SiO}_{2}$ itself is known to have relatively weak acid sites [37], which presumably release $\mathrm{NH}_{3}$ at $423-573 \mathrm{~K}$. For $\operatorname{dir}-\mathrm{SiO}_{2} / \mathrm{TiO}_{2}$, after heating at $873 \mathrm{~K}$, acid sites on $\mathrm{TiO}_{2}$ were still observed due to the possible appreciable permeability of $\mathrm{SiO}_{2}$. However, dir- $\mathrm{SiO}_{2} / \mathrm{TiO}_{2}$ heated at $973 \mathrm{~K}$ showed very weak acid sites on $\mathrm{SiO}_{2}$. This is attributable to shrinkage of the $\mathrm{SiO}_{2}$ network, prohibiting $\mathrm{NH}_{3}$ permeation. A plausible explanation is that the inner acid sites of $\mathrm{SiO}_{2}$ were also blocked and only surface acid sites were detected. As for the $\mathrm{NH}_{3}$-TPD pattern for $\mathrm{SiO}_{2}(1.5) /$ void/TiO 2 , though some shrinkage of $\mathrm{SiO}_{2}$ also occurred, the porosity still allowed some permeation of $\mathrm{NH}_{3}$. Some of the acid sites on $\mathrm{TiO}_{2}$ seemed to be hidden by the shrunken $\mathrm{SiO}_{2}$ shell, and thus the peak corresponding to $\mathrm{TiO}_{2}$ acidity was observed with a decreased intensity. It is assumed that combustion of the carbon layer by calcination at $873 \mathrm{~K}$ induced raise of effective temperature due to heat of combustion to be between $873 \mathrm{~K}$ and $973 \mathrm{~K}$. The broad but small peak at 423-573 K shows the $\mathrm{SiO}_{2}$ acidity. It should be pointed out that the $\mathrm{NH}_{3}-\mathrm{TPD}$ analyses were carried out under vacuum in the absence of water. The acidity measured in this study does not correspond directly to the acidity of the photocatalyst samples during the reaction, since photocatalytic reactions were carried out in aqueous solutions, as described later.

Attempts to prepare $\mathrm{SiO}_{2} /$ void/TiO 2 by using platinized $\mathrm{TiO}_{2}$ as the starting material were also made. However, upon inspection with SEM, it was observed that a hollow core-shell structure, as was seen for $\mathrm{SiO}_{2} /$ void/TiO $\mathrm{T}_{2}$ prepared by the standard procedure, was not formed. It has already been reported [22] the $\mathrm{TiO}_{2}$ surface must be treated with APS before the carbon-layer coating for uniform coverage of carbon on the surface of $\mathrm{TiO}_{2}$. Since $\mathrm{TiO}_{2}$ already has $\mathrm{Pt}$ particles on its surface, this might have prevented the formation of a uniform layer of carbon on $\mathrm{TiO}_{2}$ to inhibit the formation of hollow core-shell particles. The experimental results discussed in the following section clearly showed that the $\mathrm{SiO}_{2}$ shell of $\mathrm{SiO}_{2} /$ void $/ \mathrm{TiO}_{2}$ was porous, at least suspended in water, enough to allow diffusion of the platinum source to be deposited on the inner $\mathrm{TiO}_{2}$-core surface. 


\subsection{Photocatalytic activity comparison between $\mathrm{TiO}_{2}$ and photocatalysts derived from $\mathrm{TiO}_{2}$}

Figure 8 shows time-course curves of $\mathrm{H}_{2}$ liberation from aqueous methanol solutions in the second step of the platinization (see Experimental), as has been reported in the preliminary paper [30]. An almost linear increase in the amount of $\mathrm{H}_{2}$ was observed after an appreciable induction period for all of the samples except for $\operatorname{dir}-\mathrm{SiO}_{2} / \mathrm{TiO}_{2}$. This suggests that reduction of the platinum complex to metallic a state by photoexcited electrons in $\mathrm{TiO}_{2}$, to give photocatalytic activity for methanol dehydrogenation, required 5-10 min of irradiation. As shown in this figure, $\operatorname{dir}-\mathrm{SiO}_{2} / \mathrm{TiO}_{2}$ was almost inactive with negligible $\mathrm{H}_{2}$ liberation, possibly due to retardation of the adsorption of substrates, methanol and $\mathrm{H}_{2} \mathrm{PtCl}_{6}$, participating in the reaction, onto the $\mathrm{TiO}_{2}$ surface by the covering $\mathrm{SiO}_{2}$ layer to result in practically no Pt deposition. The activity of $\mathrm{SiO}_{2} / v o i d / \mathrm{TiO}_{2}$ was almost the same as that of bare $\mathrm{TiO}_{2}$ despite the presence of an $\mathrm{SiO}_{2}$ shell and was even higher than that of mec- $-\mathrm{SiO}_{2}+\mathrm{TiO}_{2}$. These facts strongly suggest that the $\mathrm{SiO}_{2}$ layer of $\mathrm{SiO}_{2} /$ void/TiO 2 has no influence on the diffusion of substrates of photocatalytic reactions.

SEM images of the photocatalysts after the platinization process are shown in Fig. 9. For platinized $\mathrm{TiO}_{2}$ (Fig. 9 (a)), well-dispersed Pt particles on $\mathrm{TiO}_{2}$ could clearly be seen. As for platinized mec- $\mathrm{SiO}_{2}+\mathrm{TiO}_{2}$ (Fig. 9 (b)), Pt particles can be seen on some parts of the sample, presumably on the $\mathrm{TiO}_{2}$ component but not on the $\mathrm{SiO}_{2}$ component. As expected, no Pt particles can be seen on $\operatorname{dir}-\mathrm{SiO}_{2} / \mathrm{TiO}_{2}$ (Fig. 9 (c)), proving that deposition of Pt was unsuccessful for this sample. The SEM image for $\mathrm{SiO}_{2}(0.5) / \mathrm{void} / \mathrm{TiO}{ }_{2}$ (Fig. 9 (d)) clearly indicated the deposition of fine Pt particles onto $\mathrm{TiO}_{2}$ without any collapse of the $\mathrm{SiO}_{2}$ shells during the platinization process. Similar results were obtained in our previous study and can be attributed to the presence of pores in the $\mathrm{SiO}_{2}$ shell and void spaces between the shell and core $\mathrm{TiO}_{2}$ particles [22]. These structures led to efficient mass transfers through an $\mathrm{SiO}_{2}$ shell to supply Pt particles to the naked active surface of the $\mathrm{TiO}_{2}$ core.

Another important feature suggested by the SEM images is the toughness of the $\mathrm{SiO}_{2}$ layers for maintaining the core-shell structure even under the condition of vigorous magnetic 
stirring during the platinization process. This may be due to the plausible flexibility of morphology of the $\mathrm{SiO}_{2}$ shell in an aqueous suspension by swelling with water; the $\mathrm{SiO}_{2}$ shell may behave like a highly water-swollen transparent liquid glass in an aqueous suspension and this would induce high flexibility and permeability for the reaction substrates.

\subsection{Redox-combined stereo-selective synthesis of L-pipecolinic acid from L-lysine}

Photocatalytic activities of the prepared samples were examined using redox-combined stereo-selective synthesis of L-PCA from L-Lys. Table 1 summarizes the results for synthesis of L-PCA from L-Lys after 2-h photoirradiation using various $\mathrm{TiO}_{2}$ photocatalysts loaded with $2 \mathrm{wt} \%$ Pt. Photoirradiation of the $\mathrm{TiO}_{2}$ photocatalysts suspended in aqueous solutions of L-Lys under Ar led to the formation of PCA, as reported previously [27,38]. Complete consumption of L-Lys was achieved using platinized bare $\mathrm{TiO}_{2}$ (entry 1 ) and also $m e c-\mathrm{SiO}_{2}+\mathrm{TiO}_{2}$ (entry 2). These photocatalysts showed almost the same results in terms of selectivity based on amount of consumed L-Lys $\left(\mathrm{S}_{\mathrm{PCA}}\right)$, optical purity $\left(\mathrm{OP}_{\mathrm{PCA}}\right.$; $([\mathrm{L}-\mathrm{Lys}]-[\mathrm{D}-\mathrm{Lys}]) /([\mathrm{L}-\mathrm{Lys}]+[\mathrm{D}-\mathrm{Lys}]))$ and rate of PCA formation in the unit of $\mu \mathrm{mol} \mathrm{h}{ }^{-1}$ $\left(\mathrm{R}_{\mathrm{PCA}}\right)$, suggesting that the mechanical mixing of $\mathrm{SiO}_{2}$ with $\mathrm{TiO}_{2}$ does not have any effect on this reaction as only the $\mathrm{TiO}_{2}$ part was responsible for the photocatalytic reaction. As expected, dir- $\mathrm{SiO}_{2} / \mathrm{TiO}_{2}$ (entry 3 ) showed poor photocatalytic activity with conversion of only $14 \%$ of L-Lys (and only $2 \mu \mathrm{mol}$ of $\mathrm{H}_{2}$ ), suggesting that direct coverage of the $\mathrm{TiO}_{2}$ surface with $\mathrm{SiO}_{2}$ hinders the activity of $\mathrm{TiO}_{2}$ by prohibiting $\mathrm{Pt}$ deposition as well as L-Lys adsorption onto the bare $\mathrm{TiO}_{2}$ surface.

The performance of $\mathrm{SiO}_{2}(0.5) /$ void/ $\mathrm{TiO}_{2}$ particles (entry 4) prepared with a $0.5-\mathrm{h}$ silylation period was almost the same as that of bare $\mathrm{TiO}_{2}$ (entry 1). Although the selectivity was only slightly lower than that of bare $\mathrm{TiO}_{2}, \mathrm{SiO}_{2} /$ void/TiO 2 exhibited the highest $\mathrm{OP}_{\mathrm{PCA}}$, 13\% more than that of platinized bare $\mathrm{TiO}_{2}$, among all of the samples. In order to further prove the effectiveness of the hollow core-shell structure, the photocatalytic performance of

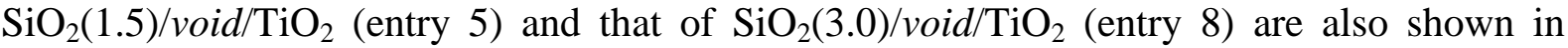
Table 1. While $\mathrm{SiO}_{2}(1.5) /$ void/ $\mathrm{TiO}_{2}$, having a slightly thicker $\mathrm{SiO}_{2}$ layer, exhibited the best 
performance among the tested samples, it seemed that the photocatalytic performance (conversion, $\mathrm{S}_{\mathrm{PCA}}, \mathrm{OP}_{\mathrm{PCA}}$ and $\mathrm{R}_{\mathrm{PCA}}$ ) was not greatly changed by the $\mathrm{SiO}_{2}$ shell thickness. This is consistent with the possible high permeability of the $\mathrm{SiO}_{2}$ shell.

In order to further investigate the effect of the hollow core-shell structure, $\mathrm{SiO}_{2} /$ void/TiO 2 samples with different void space sizes were also prepared and their photocatalytic performances for synthesis of L-PCA from L-Lys were examined, as shown in Table 1. With smaller void space $\left(\mathrm{SiO}_{2}(1.5) / 0.5\right.$ void/ $/ \mathrm{TiO}_{2}$ prepared with a lower glucose concentration $\left(0.25 \mathrm{~mol} \mathrm{dm}^{-3}\right.$; entry 6$), \mathrm{R}_{\mathrm{PCA}}$ was decreased by $4 \%$ (2\% decrease in conversion) and $\mathrm{OP}_{\mathrm{PCA}}$ was increased by $2 \%$ compared with those of the sample prepared with the standard glucose concentration $\left(0.5 \mathrm{~mol} \mathrm{dm}^{-3}\right.$; entry 5$)$. Although the improvement of $\mathrm{OP}_{\mathrm{PCA}}$ was not so obvious, rate reduction was distinct. On the other hand, when the void space was increased by using a higher glucose concentration (1.0 mol dm${ }^{-3}$; entry 7$)$, L-Lys

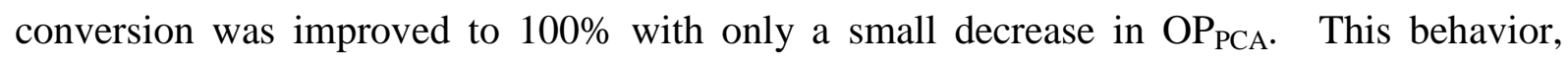
influence of void-space thickness, can be explained by water-induced swelling of the $\mathrm{SiO}_{2}$ shell; the swelling by water, i.e., expansion of shell thickness, may reduce the void-space size, and for the sample of $\mathrm{SiO}_{2}(1.5) / 0.5 \mathrm{void} / \mathrm{TiO}_{2}$, the void space reduction might cause contact of $\mathrm{SiO}_{2}$ with the $\mathrm{TiO}_{2}$ surface to interfere with the approach of the substrate L-Lys, while for the sample of $\mathrm{SiO}_{2}(1.5) / 2.0$ void/ $/ \mathrm{TiO}_{2}$ with a larger void space, such direct contact of swollen $\mathrm{SiO}_{2}$ and $\mathrm{TiO}_{2}$ is neglected to obtain higher L-Lys conversion. Thus, a larger void space seems preferable for higher L-Lys conversion, i.e., reaction rate, but it is expected that a sample with a larger void space than that of $\mathrm{SiO}_{2}(1.5) / 2.0$ void/TiO $\mathrm{Ti}_{2}$ will show lower $\mathrm{OP}_{\mathrm{PCA}}$ because of the improbable effect of $\mathrm{SiO}_{2}$ acidity, as will be discussed in the following section. Considering that the bare $\mathrm{TiO}_{2}$, which can be an utmost limit of larger void space, showed a higher rate and lower $\mathrm{OP}_{\mathrm{PCA}}$, a swollen $\mathrm{SiO}_{2}$ shell close to, but not in contact with, the $\mathrm{TiO}_{2}$ surface, where the photocatalytic reaction proceeds, is a key for higher L-Lys conversion and higher $\mathrm{OP}_{\mathrm{PCA}}$.

As mentioned in the preceding section, PCA production from L-Lys proceeds through a redox-combined mechanism as shown in Scheme 1 [28]. According to this 
mechanism, $\mathrm{OP}_{\mathrm{PCA}}$ is regulated by (1) selectivity in the position in the first step of amino-group oxidation and (2) difference in efficiency in the following second step of Schiff-base reduction into PCA between $\varepsilon$ and $\alpha$-routes; $\mathrm{S}_{\mathrm{PCA}}$ corresponds to the average efficiency of the second process. Assuming the same efficiency of the second reduction step for $\alpha$ and $\varepsilon$-routes, $\mathrm{OP}_{\mathrm{PCA}}$ shows the proportion of the $\varepsilon$-route, since $\varepsilon$ and $\alpha$-routes yield $\mathrm{L}$ and racemic PCA, respectively. This has been proved in a previous study [28] by the fact that $\mathrm{OP}_{\mathrm{PCA}}$ was almost the same as the proportion of ${ }^{15} \mathrm{~N}$ inclusion in PCA from $\alpha_{-}{ }^{15} \mathrm{~N}$-labeled L-Lys. A possible reason for improved $\mathrm{OP}_{\mathrm{PCA}}$, with almost the same $\mathrm{S}_{\mathrm{PCA}}$, by the use of $\mathrm{SiO}_{2} /$ void/ $/ \mathrm{TiO}_{2}$ is increase in proportion of the $\varepsilon$-route, presumably due to the acidic character of $\mathrm{SiO}_{2}[39]$ being close to the core $\mathrm{TiO}_{2}$ surface.

It has been observed that reaction at lower $\mathrm{pH}$ improved $\mathrm{OP}_{\mathrm{PCA}}$ and decreased $\mathrm{R}_{\mathrm{PCA}}$ when platinized (bare) $\mathrm{TiO}_{2}$ particles were used as the photocatalyst [41]. Because of the higher basicity of the $\varepsilon$-amino group than that of $\alpha$-amino group, the $\varepsilon$-amino group is protonated to be an ammonium group $\left(-\mathrm{NH}_{3}{ }^{+}\right)$, compensating the negative charge of carboxylate and leaving the $\alpha$-amino group in neutral form under the conditions employed in this study. Taking into account the higher (more anodic) oxidation potential of an ammonium form than that of a natural amino form into, preferential oxidation of the $\varepsilon$-amino group cannot be expected with ordinary aqueous solutions. At lower $\mathrm{pH}$, both $\alpha$ and $\varepsilon$-amino groups are protonated and thereby the reaction rate is decreased, while relative reactivity of the $\varepsilon$-amino group to undergo oxidation by positive holes is enhanced. This is the most probable interpretation of improved $\mathrm{OP}_{\mathrm{PCA}}$ at lower $\mathrm{pH}$. However, as the stoichiometry of the reaction shows, PCA production accompanies $\mathrm{NH}_{3}$ release and even when a suspension is acidified before reaction, the released $\mathrm{NH}_{3}$ may be neutralized; $\mathrm{OP}_{\mathrm{PCA}}$ becomes low unless buffer solutions, which may reduce the photocatalytic reaction rate further, are used [41]. As reported previously [38], blocking of the $\varepsilon$-amino group by carbamoyl derivatization not to be protonated and thereby preferential protonation of the $\alpha$-amino group in Lys led to the production of optically pure L-PCA. It is clear that this is a good strategy for pure L-PCA synthesis, but selective carbamoyl derivatization is needed; use 
of bare L-Lys, a cheap starting material, without derivatization is preferable. In this sense, higher $\mathrm{OP}_{\mathrm{PCA}}$ by $\mathrm{SiO}_{2} /$ void/ $/ \mathrm{TiO}_{2}$ in the present study might be a breakthrough for selective synthesis. Since it has been observed that crystallization of PCA of higher OP $_{\text {PCA }}$ gave almost pure L-PCA due to exclusion of D-PCA from L-PCA crystallites [38], higher $\mathrm{OP}_{\mathrm{PCA}}$, even lower than $100 \%$, is beneficial for practical application to L-PCA synthesis.

The possible acidic microenvironment of the core $\mathrm{TiO}_{2}$ surface induced by the water-swollen $\mathrm{SiO}_{2}$ shell might lead to protonation of the $\alpha$-amino group to result in retardation of $\alpha$-route due to higher (more anodic) oxidation potential of the ammonium form of amino groups in Lys. As was discussed in the preceding section, though the acid strength and amount of acidic sites in the $\mathrm{SiO}_{2}$ shell seem not to be high and large, respectively, when measured under dried conditions, the appreciable acidity of the $\mathrm{SiO}_{2}$ shell close to, but not in contact with, the core $\mathrm{TiO}_{2}$ surface can account for the improved OP $\mathrm{PCA}_{\mathrm{P}}$ by promoting protonation of an $\alpha$-amino group in L-Lys.

Since the acidity provided by the $\mathrm{SiO}_{2}$ shell may have been the factor in the improvement of optical purity of PCA, modifications with $\mathrm{H}_{2} \mathrm{SO}_{4}$ or MPTS to introduce sulfonic acid groups to the surface of $\mathrm{SiO}_{2}$ in $\mathrm{SiO}_{2} /$ void/TiO $\mathrm{TiO}_{2}$ were attempted in order to increase the acidity. For the MPTS-modified sample, $\mathrm{SiO}_{2} /$ void/TiO $\mathrm{Ti}_{2}+\mathrm{MPTS}$, it was expected that the MPTS moiety introduced presumably in the $\mathrm{SiO}_{2}$ shell was oxidized into a sulfonic acid group in the calcination process in air. We tried to measure the content of sulfur in these modified $\mathrm{SiO}_{2} /$ void/TiO ${ }_{2}$ samples and to clarify its chemical form, but we failed presumably due to the low concentration and the limit of samples prepared for one autoclave operation.

The modified $\mathrm{SiO}_{2} /$ void/ $/ \mathrm{TiO}_{2}$ particles were then used as photocatalysts in the synthesis of PCA from L-Lys, and the results are summarized in Table 2. The conversions for all three of these photocatalysts were relatively high, indicating that these modifications did not hinder the activity of the photocatalyst. For the hollow core-shell particles modified with $\mathrm{H}_{2} \mathrm{SO}_{4}$, slight increases in $\mathrm{OP}_{\mathrm{PCA}}$ and $\mathrm{R}_{\mathrm{PCA}}$ were observed. However, the $\mathrm{S}_{\mathrm{PCA}}$ decreased to less than $50 \%$ with this modification. As for $\mathrm{SiO}_{2} /$ void/TiO $2+\mathrm{MPTS}, \mathrm{S}_{\mathrm{PCA}}$ 
recorded exceeded 50\% and $\mathrm{OP}_{\mathrm{PCA}}$ was also the highest among these modified photocatalysts, though the conversion was only $85 \%$. In order to increase L-Lys conversion using $\mathrm{SiO}_{2} /$ void/TiO $2+\mathrm{MPTS}$ as the photocatalyst, the reaction was prolonged for another $0.5 \mathrm{~h}$ to $2.5 \mathrm{~h}$. As shown in Table 2, the reactant was almost fully converted with the maintenance of high values of $\mathrm{S}_{\mathrm{PCA}}$ and $\mathrm{OP}_{\mathrm{PCA}}$. Based on these results, the modifications gave a positive effect to the photocatalytic ability of $\mathrm{SiO}_{2} /$ void/ $/ \mathrm{TiO}_{2}$ in this reaction, with modifications with MPTS being more beneficial. This further proved the possibility of an acidic microenvironment of the core $\mathrm{TiO}_{2}$ surface induced by the $\mathrm{SiO}_{2}$ shell and also the MPTS that led to protonation of the $\alpha$-amino group to result in retardation of the $\alpha$-route, as mentioned earlier, being the possible reason for the production of optically pure L-PCA.

\section{Conclusions}

In this study, we have shown that platinized $\mathrm{SiO}_{2} /$ void/TiO ${ }_{2}$, composed of commercially available $\mathrm{TiO}_{2}$ photocatalyst particles encapsulated in hollow $\mathrm{SiO}_{2}$ shells, shows high photocatalytic performance for inducing selective production of L-PCA from L-Lys while maintaining a level of activity, i.e., rate of Lys conversion, comparable to that of original bare $\mathrm{TiO}_{2}$, presumably due to the slightly acidic microenvironment of the core $\mathrm{TiO}_{2}$ surface induced by the $\mathrm{SiO}_{2}$ shells. The higher PCA selectivity $\left(\mathrm{S}_{\mathrm{PCA}}\right)$ and optical purity $\left(\mathrm{OP}_{\mathrm{PCA}}\right)$ of $\mathrm{SiO}_{2} /$ void/TiO $/ \mathrm{TiO}_{2}$ were almost independent of thickness of the $\mathrm{SiO}_{2}$ shell, suggesting that the $\mathrm{SiO}_{2}$ shell was greatly swollen by water and was permeable for the substrates and products of the photocatalytic reaction. On the other hand, the size of void space between the $\mathrm{SiO}_{2}$ shell and the $\mathrm{TiO}_{2}$ core had an appreciable influence on performance, i.e., the smaller void space induced a slower rate and higher $\mathrm{OP}_{\mathrm{PCA}}$ and a larger void space induced a higher rate and lower $\mathrm{OP}_{\mathrm{PCA}}$. These facts suggest that the best performance is obtained when the water-swollen $\mathrm{SiO}_{2}$ shell is almost in contact with the $\mathrm{TiO}_{2}$ surface without covering the surface based on the assumption that the $\mathrm{SiO}_{2}$ shell in an aqueous suspension behaves as a highly porous, flexible and swollen liquid medium having appreciable, but not strong, acidity to control the protonation-deprotonation equilibria of $\alpha$ and $\varepsilon$-amino groups in L-Lys. Thus, 
$\mathrm{SiO}_{2} /$ void/ $/ \mathrm{TiO}_{2}$ provides an advantageous microenvironment for selective L-PCA synthesis without addition of any chemicals such as an acid or a buffer solution, which must be separated in the post reaction procedure. Further improvement of photocatalytic performance of $\mathrm{SiO}_{2} /$ void/ $\mathrm{TiO}_{2}$ was achieved by modification of the $\mathrm{SiO}_{2}$ shell with a possibly sulfonic acid moiety; the highest $\mathrm{OP}_{\mathrm{PCA}}$ of $75 \%$ was obtained, though further improvement of $\mathrm{OP}_{\mathrm{PCA}}$ is still needed. It is expected that more precise control of the appropriate size of the void space between the core and shell and design of silica-shell structures will also improve the performance of photocatalysts for stereoselective synthesis of L-PCA, and study along this line is now in progress. The present results may open a new field of material chemistry for designing the microenvironment of a photocatalyst surface to control reaction selectivity.

\section{Acknowledgments}

The authors thank Professors Wataru Ueda, Toru Murayama and Yuichi Kamiya (Hokkaido University) for their help in ammonia TPD analyses. Professor Shigeru Ikeda (Osaka University) is gratefully acknowledged for his advice on sample preparation.

\section{References}

[1] A. Fujishima, X. T. Zhang, D. A. Tryk, $\mathrm{TiO}_{2}$ photocatalysis and related surface phenomena, Surf. Sci. Rep. 63(2008) 515-582.

[2] M. R. Hoffmann, S. T. Martin, W. Y. Choi, D. W. Bahnemann, Environmental applications of semiconductor photocatalysis, Chem. Rev. 95 (1995) 69-96.

[3] H. Yoshida, H. Yuzawa, M. Aoki, K. Otake, H. Itoh, T. Hattori, Photocatalytic hydroxylation of aromatic ring by using water as an oxidant, Chem. Commun. (2008) 4634-4636.

[4] K. Imamura, S. Iwasaki, T. Maeda, K. Hashimoto, B. Ohtani, H. Kominami, Photocatalytic reduction of nitrobenzenes to aminobenzenes in aqueous suspensions of 
titanium(IV) oxide in the presence of hole scavengers under deaerated and aerated conditions, Phys. Chem. Chem. Phys. 13 (2011) 5114-5119.

[5] J. S. Lee, W. Y. Choi, Effect of platinum deposits on $\mathrm{TiO}_{2}$ on the anoxic photocatalytic degradation pathways of alkylamines in water: Dealkylation and N-alkylation, Environ. Sci. Technol. 38 (2004) 4026-4033.

[6] O. Tomita, R. Abe, B. Ohtani, Direct synthesis of phenol from benzene over platinum-loaded tungsten(VI) oxide photocatalysts with water and molecular oxygen, Chem. Lett. 40 (2011) 1405-1407.

[7] B. Ohtani, B. Pal, S. Ikeda, Photocatalytic organic syntheses: selective cyclization of amino acids in aqueous suspensions, Catal. Surv. Asia 7 (2003) 165-176.

[8] Y. Shiraishi, T. Hirai, Selective organic transformations on titanium oxide-based photocatalysts, J. Photochem. Photobiol. C-Photochem. Rev. 9 (2008) 157-170.

[9] M. A. Fox, M. T. Dulay, Heterogeneous photocatalysis, Chem. Rev. 93 (1993) 341-357.

[10] Y. Shiraishi, N. Saito, T. Hirai, Adsorption-driven photocatalytic activity of mesoporous titanium dioxide, J. Am. Chem. Soc. 127 (2005) 12820-12822.

[11] J. G. Yu, J. C. Yu, M. K. P. Leung, W. K. Ho, B. Cheng, X. J. Zhao, J. C. Zhao, Effects of acidic and basic hydrolysis catalysts on the photocatalytic activity and microstructures of bimodal mesoporous titania, J. Catal. 217 (2003) 69-78.

[12] Y. M. Xu, C. H. Langford, Photoactivity of titanium dioxide supported on MCM41, zeolite X, and zeolite Y, J. Phys. Chem. B, 101 (1997) 3115-3121.

[13] L. Davydov, E. P. Reddy, P. France, P.G. Smirniotis, Transition-metal-substituted titania-loaded MCM-41 as photocatalysts for the degradation of aqueous organics in visible light, J. Catal. 203 (2001) 157-167.

[14] G. Cosa, M. S. Galletero, L. Fernandez, F. Marquez, H. Garcia, J. C. Scaiano, Tuning the photocatalytic activity of titanium dioxide by encapsulation inside zeolites exemplified by the cases of thianthrene photooxygenation and horseradish peroxidase photodeactivation, New J. Chem. 26 (2002) 1448-1455. 
[15] F. Xamena, P. Calza, C. Lamberti, C. Prestipino, A. Damin, S. Bordiga, E. Pelizzetti, A. Zecchina, Enhancement of the ETS-10 titanosilicate activity in the shape-selective photocatalytic degradation of large aromatic molecules by controlled defect production, J. Am. Chem. Soc. 125 (2003) 2264-2271.

[16] M. Morishita, Y. Shiraishi, T. Hirai, Ti-containing mesoporous organosilica as a photocatalyst for selective olefin epoxidation, J. Phys. Chem. B 110 (2006) 17898-17905.

[17] S. Ikeda, Y. Kowata, K. Ikeue, M. Matsumura, B. Ohtani, Asymmetrically modified titanium(IV) oxide particles having both hydrophobic and hydrophilic parts of their surfaces for liquid-liquid dual-phase photocatalytic reactions, Appl. Catal. A Gen. 265 (2004) 69-74.

[18] K. Inumaru, T. Kasahara, M. Yasui, S. Yamanaka, Direct nanocomposite of crystalline $\mathrm{TiO}_{2}$ particles and mesoporous silica as a molecular selective and highly active photocatalyst, Chem. Commun. (2005) 2131-2133.

[19] S. Shanmugam, A. Gabashvili, D. S. Jacob, J. C. Yu, A. Gedanken, Synthesis and characterization of $\mathrm{TiO}_{2} @ \mathrm{C}$ core-shell composite nanoparticles and evaluation of their photocatalytic activities, Chem. Mater 18 (2006) 2275-2282.

[20] T. Ohno, T. Tsubota, K. Kakiuchi, S. Miyayarna, K. Sayama, Selective oxidation of aldehydes on $\mathrm{TiO}_{2}$ photocatalysts modified with functional groups, J. Mol. Catal. A Chem. 245 (2006) 47-54.

[21] S. Ikeda, Y. Ikoma, H. Kobayashi, T. Harada, T. Torimoto, B. Ohtani, M. Matsumura, Encapsulation of titanium(IV) oxide particles in hollow silica for size-selective photocatalytic reactions, Chem. Commun (2007) 3753-3755.

[22] S. Ikeda, H. Kobayashi, Y. Ikoma, T. Harada, T. Torimoto, B. Ohtani, M. Matsumura, Size-selective photocatalytic reactions by titanium(IV) oxide coated with a hollow silica shell in aqueous solutions, Phys. Chem. Chem. Phys. 9 (2007) 6319-6326.

[23] S. Ikeda, H. Kobayashi, Y. Ikoma, T. Harada, S. Yamazaki, M. Matsumura, Structural effects of titanium(IV) oxide encapsulated in a hollow silica shell on photocatalytic 
activity for gas-phase decomposition of organics, Appl. Catal. A Gen. 369 (2009) 113-118.

[24] S. Ikeda, H. Kobayashi, T. Sugita, Y. Ikoma, T. Harada, M. Matsumura, Efficient photodecomposition of gaseous organics catalyzed by titanium(IV) oxide encapsulated in a hollow silica shell with high porosity, Appl. Catal. A Gen. 363 (2009) 216-220.

[25] P. D. Bailey, P. A. Millwood, P. D. Smith, Asymmetric routes to substituted piperidines, Chem. Commun. (1998) 633-640.

[26] B. T. A Ekenstam, C. Bovin, L-N-n-propylpipecolic acid-2,6-xylidide. US Patent (1987) 4695576.

[27] B. Pal, S. Ikeda, H. Kominami, Y. Kera, B. Ohtani, Photocatalytic redox-combined synthesis of L-pipecolinic acid from L-lysine by suspended titania particles: effect of noble metal loading on the selectivity and optical purity of the product, J. Catal. 217 (2003) 152-159.

[28] B. Ohtani, S. Tsuru, S. Nishimoto, T. Kagiya, K. Izawa, Photocatalytic one-step syntheses of cyclic imino acids by aqueous semiconductor suspensions, J. Org. Chem. 55 (1990) 5551-5553.

[29] B. Ohtani, K. Iwai, H. Kominami, T. Matsuura, Y. Kera, S. Nishimoto, Titanium(IV) oxide photocatalyst of ultra-high activity for selective $\mathrm{N}$-cyclization of an amino-acid in aqueous suspensions, Chem. Phys. Lett. 242 (1995) 315-319.

[30] S. Chandren, B. Ohtani, Preparation and reaction of titania particles encapsulated in hollow silica shells as an efficient photocatalyst for stereoselective synthesis of pipecolinic acid, Chem. Lett. 41 (2012) 677-679.

[31] C. Graf, D. L. J. Vossen, A. Imhof, A. van Blaaderen, A general method to coat colloidal particles with silica, Langmuir 19 (2003) 6693-6700.

[32] B. Ohtani, K. Iwai, S. Nishimoto, S. Sato, Role of platinum deposits on titanium(IV) oxide particles: Structural and kinetic analyses of photocatalytic reaction in aqueous alcohol and amino acid solutions, J. Phys. Chem. B 101 (1997) 3349-3359.

[33] X. M. Sun, Y. D. Li, Colloidal carbon spheres and their core/shell structures with 
noble-metal nanoparticles, Angew. Chem. Int. Ed. 43 (2004) 597-601.

[34] J. C. Groen, L. A. A. Peffer, J. Perez-Ramirez, Pore size determination in modified micro- and mesoporous materials. Pitfalls and limitations in gas adsorption data analysis, Micropor. Mesopor. Mater. 60 (2003) 1-17.

[35] I. Tissot, J. P. Reymond, F. Lefebvre, E. Bourgeat-Lami, SiOH-functionalized polystyrene latexes. A step toward the synthesis of hollow silica nanoparticles, Chem. Mater. 14 (2002) 1325-1331.

[36] Y. Lu, J. McLellan, Y. N. Xia, Synthesis and crystallization of hybrid spherical colloids composed of polystyrene cores and silica shells, Langmuir 20 (2004) 3464-3470.

[37] P. J. Kropp, G. W. Breton, S. L. Craig, S. D. Crawford, W. F. Durland, J. E. Jones, J. S. Raleigh, Surface-mediated reactions. 6. Effects of silica-gel and alumina on acid catalyzed reactions, J. Org. Chem. 60 (1995) 4146-4152.

[38] B. Ohtani, E. Aoki, K. Iwai, and S.-i. Nishimoto, Photocatalytic synthesis of L-pipecolinic acid from Ne-Carbamyl-L-lysine by aqueous suspension of platinized titanium(IV) oxide, J. Photosci. 1 (1994) 31-37.

[39] B. Ohtani, K. Iwai, S. Nishimoto, T. Inui, Electrochromism of niobium oxide thin-films prepared by the sol-gel process, J. Electrochem. Soc. 141 (1994) $2439-2442$.

[40] K.C. Akratopulu, L. Vordonis, A. Lycourghiotis, Development of carriers with controlled concentration of charged surface groups in aqueous solutions: III. Regulation of the point of zero charge, surface dissociation constants, and concentration of charged surface groups of $\mathrm{SiO}_{2}$ by variation of the solution temperature or by modification with sodium ions, J. Catal. 109 (1988) 41-50.

[41] B. Ohtani, S. Tsuru, unpublished results. 
Table 1 Synthesis of PCA from L-Lys using various platinized $\mathrm{TiO}_{2}$ photocatalysts suspended in a deaerated solution by 2-h irradiation with a mercury arc.

\begin{tabular}{|c|c|c|c|c|c|c|}
\hline Entry. & Photocatalyst & $\begin{array}{c}\text { Conversion } \\
(\%)\end{array}$ & $\begin{array}{l}\mathrm{S}_{\mathrm{PCA}}{ }^{\mathrm{a}} \\
(\%)\end{array}$ & $\begin{array}{c}\mathrm{OP}_{\mathrm{PCA}}{ }^{\mathrm{b}} \\
(\%)\end{array}$ & $\mathrm{R}_{\mathrm{PCA}}{ }^{\mathrm{c}}$ & $\begin{array}{c}\mathrm{Y}_{\mathrm{H} 2}^{\mathrm{d}} \\
(\mu \mathrm{mol})\end{array}$ \\
\hline 1 & $\mathrm{TiO}_{2}$ & 100 & 51 & 57 & 27 & 75 \\
\hline 2 & $m e c-\mathrm{SiO}_{2}+\mathrm{TiO}_{2}$ & 100 & 52 & 59 & 27 & 63 \\
\hline 3 & $\operatorname{dir}-\mathrm{SiO}_{2} / \mathrm{TiO}_{2}{ }^{\mathrm{e}}$ & 14 & 26 & $-^{\mathrm{f}}$ & 0.2 & 2 \\
\hline 4 & $\mathrm{SiO}_{2}(0.5) /$ void $/ \mathrm{TiO}_{2}$ & 98 & 43 & 70 & 22 & 72 \\
\hline 5 & $\mathrm{SiO}_{2}(1.5) /$ void $/ \mathrm{TiO}_{2}$ & 96 & 50 & 70 & 25 & 50 \\
\hline 6 & $\mathrm{SiO}_{2}(1.5) / 0.5$ void $/ \mathrm{TiO}_{2}$ & 94 & 44 & 72 & 21 & 55 \\
\hline 7 & $\mathrm{SiO}_{2}(1.5) / 2.0$ void $/ \mathrm{TiO}_{2}$ & 100 & 51 & 69 & 25 & 82 \\
\hline 8 & $\mathrm{SiO}_{2}(3.0) /$ void $/ \mathrm{TiO}_{2}$ & 96 & 46 & 70 & 23 & 57 \\
\hline
\end{tabular}

${ }^{\mathrm{a}}$ Selectivity of PCA production based on amount of consumed L-Lys. ${ }^{\mathrm{b}}$ Optical purity of L-PCA. $\quad{ }^{\mathrm{c}}$ Rate of PCA formation in the unit of $\mu \mathrm{mol} \mathrm{h}^{-1}$. ${ }^{\mathrm{d}}$ Yield of $\mathrm{H}_{2}$. ${ }^{\mathrm{e}}$ Platinization via photodeposition was unsuccessful (see text). ${ }^{\mathrm{f}}$ Not determined. 
Table 2 Synthesis of PCA from L-Lys using various platinized $\mathrm{SiO}_{2} /$ void/TiO 2 (2-h photoirradiation).

\begin{tabular}{|c|c|c|c|c|c|}
\hline Catalyst & $\begin{array}{c}\text { Conversion } \\
(\%)\end{array}$ & $\begin{array}{l}\mathrm{S}_{\mathrm{PCA}}{ }^{\mathrm{a}} \\
(\%)\end{array}$ & $\begin{array}{c}\mathrm{OP}_{\mathrm{PCA}}^{\mathrm{b}} \\
(\%)\end{array}$ & $\mathrm{R}_{\mathrm{PCA}}{ }^{\mathrm{c}}$ & $\begin{array}{c}\mathrm{Y}_{\mathrm{H} 2}^{\mathrm{d}} \\
(\mu \mathrm{mol})\end{array}$ \\
\hline $\mathrm{SiO}_{2}(1.5) /$ void $/ \mathrm{TiO}_{2}$ & 96 & 50 & 70 & 25 & 50 \\
\hline $\mathrm{SiO}_{2} /$ void $/ \mathrm{TiO}_{2}+\mathrm{H}_{2} \mathrm{SO}_{4}$ & 99 & 46 & 73 & 23 & 67 \\
\hline $\mathrm{SiO}_{2} /$ void $/ \mathrm{TiO}_{2}+\mathrm{MPTS}$ & 85 & 53 & 75 & 24 & 32 \\
\hline $\mathrm{SiO}_{2} /$ void $/ \mathrm{TiO}_{2}+\mathrm{MPTS}^{\mathrm{f}}$ & 98 & 53 & 75 & 22 & 49 \\
\hline
\end{tabular}




\section{Figure captions}

Scheme 1 Proposed mechanism of the photocatalytic N-cyclization of L-Lys on platinized $\mathrm{TiO}_{2}$ particles.

Fig. 1 SEM images taken in transmission mode of (a) $\mathrm{TiO}_{2}(\mathrm{ST}-41)$, (b) $\mathrm{TiO}_{2}$ after hydrothermal treatment with an aqueous glucose solution and (c) $\mathrm{C} / \mathrm{TiO}_{2}$ after successive treatment with AEAPS and TEOS. Scale bars correspond to 100 $\mathrm{nm}$.

Fig. 2 SEM images taken in transmission mode of (a) $\mathrm{SiO}_{2}(0.5) /$ void/ $/ \mathrm{TiO}_{2}$, (b)

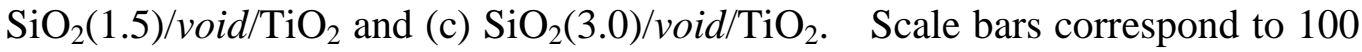
nm.

Fig.3 SEM images taken in transmission mode of $\mathrm{SiO}_{2}(1.5) /$ void/TiO $\mathrm{Ti}_{2}$ prepared with different glucose concentrations of (a) $0.25 \mathrm{~mol} \mathrm{dm}^{-3}$, (b) $0.5 \mathrm{~mol} \mathrm{dm}^{-3}$ and (c) $2.0 \mathrm{~mol} \mathrm{dm}^{-3}$. Scale bars correspond to $100 \mathrm{~nm}$.

Fig. 4 XRD patterns of (a) $\mathrm{TiO}_{2}(\mathrm{ST}-41)$ and (b) $\mathrm{SiO}_{2}(0.5) /$ void/TiO 2 .

Fig. $5 \mathrm{~N}_{2}$ adsorption-desorption isotherms of (a) $\mathrm{TiO}_{2}(\mathrm{ST}-41)$ and (b) $\mathrm{SiO}_{2} /$ void/TiO 2 . Filled and open circles denote adsorption and desorption branches, respectively.

Fig. $6 \quad \mathrm{NH}_{3}-\mathrm{TPD}$ patterns for $\mathrm{TiO}_{2}$, APS-TiO 2 and $\mathrm{C}-\mathrm{TiO}_{2}$.

Fig. $7 \quad \mathrm{NH}_{3}-\mathrm{TPD}$ patterns for $\operatorname{dir}-\mathrm{SiO}_{2} / \mathrm{TiO}_{2}, \quad \operatorname{dir}-\mathrm{SiO}_{2} / \mathrm{TiO}_{2}$ heated at $973 \mathrm{~K}$ $\left(* d i r-\mathrm{SiO}_{2} / \mathrm{TiO}_{2}\right)$ and $\mathrm{SiO}_{2}(1.5) /$ void/ $/ \mathrm{TiO}_{2}$.

Fig. 8 Time course curves of liberated $\mathrm{H}_{2}$ on $\mathrm{TiO}_{2}$ (filled circles), $\mathrm{SiO}_{2} /$ void/TiO (filled squares), $m e c-\mathrm{SiO}_{2}+\mathrm{TiO}_{2}$ (open circles) and $d i r-\mathrm{SiO}_{2} / \mathrm{TiO}_{2}$ (open squares) from an aqueous methanol solution in the presence of $\mathrm{H}_{2} \mathrm{PtCl}_{6}$.

Fig. 9 SEM images taken in transmission mode of platinized (a) $\mathrm{TiO}_{2}$, (b) $m e c-\mathrm{SiO}_{2}+\mathrm{TiO}_{2}$, (c) dir- $\mathrm{SiO}_{2} / \mathrm{TiO}_{2}$ and (d) $\mathrm{SiO}_{2}(0.5) / v o i d / \mathrm{TiO}_{2}$. Scale bars correspond to $100 \mathrm{~nm}$. 


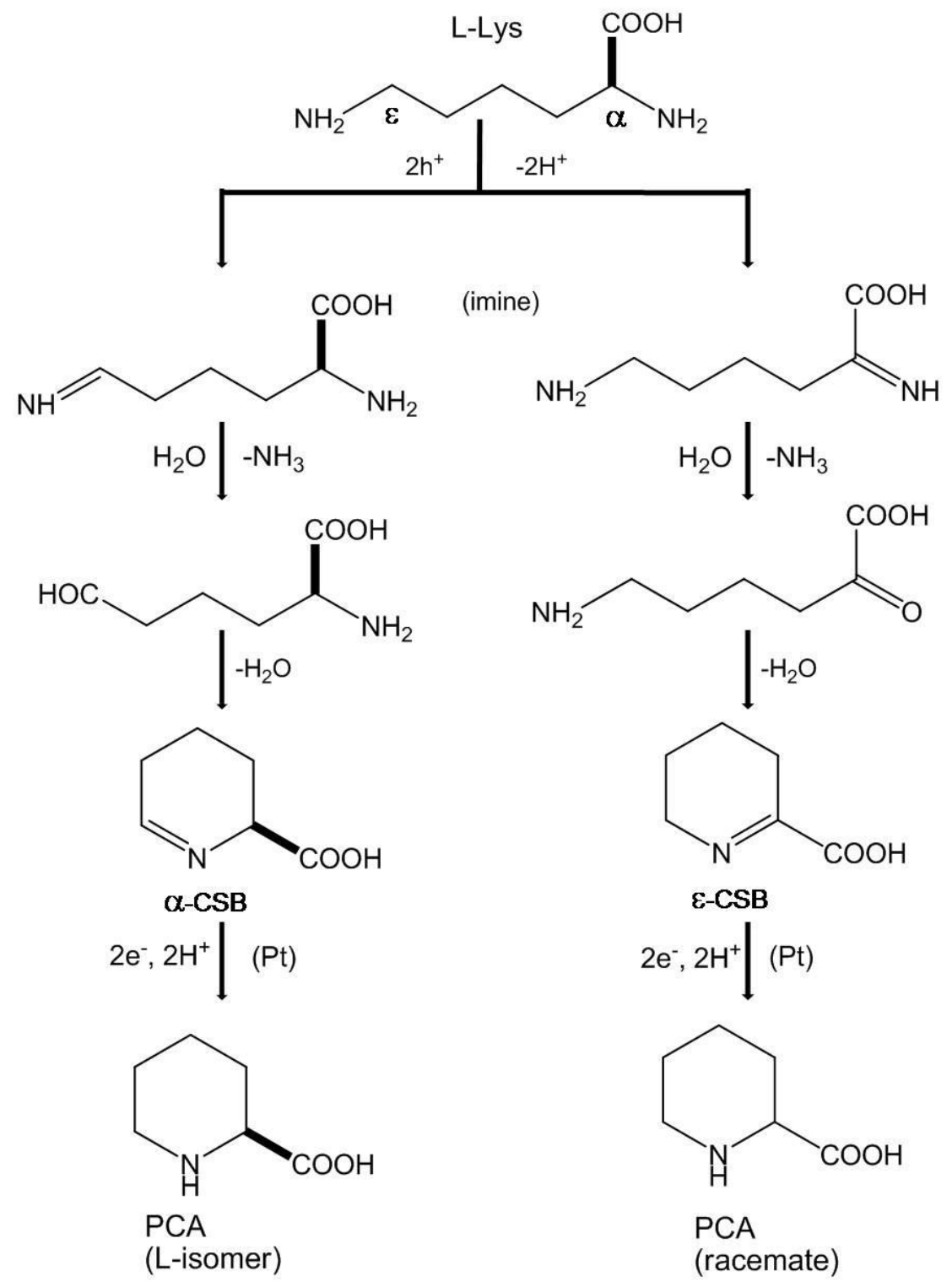

Scheme 1 Proposed mechanism of the photocatalytic N-cyclization of L-Lys on platinized $\mathrm{TiO}_{2}$ particles. 


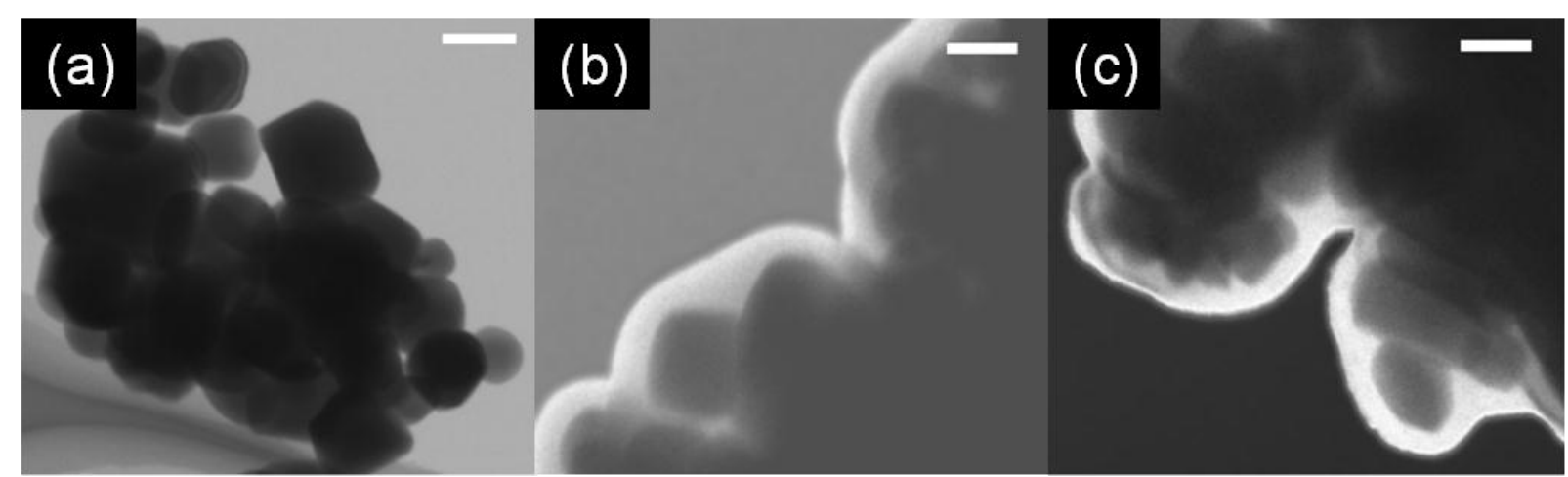

Fig. 1 SEM images taken in transmission mode of (a) $\mathrm{TiO}_{2}(\mathrm{ST}-41)$, (b) $\mathrm{TiO}_{2}$ after hydrothermal treatment with an aqueous glucose solution and (c) $\mathrm{C} / \mathrm{TiO}_{2}$ after successive treatment with AEAPS and TEOS. Scale bars correspond to $100 \mathrm{~nm}$. 


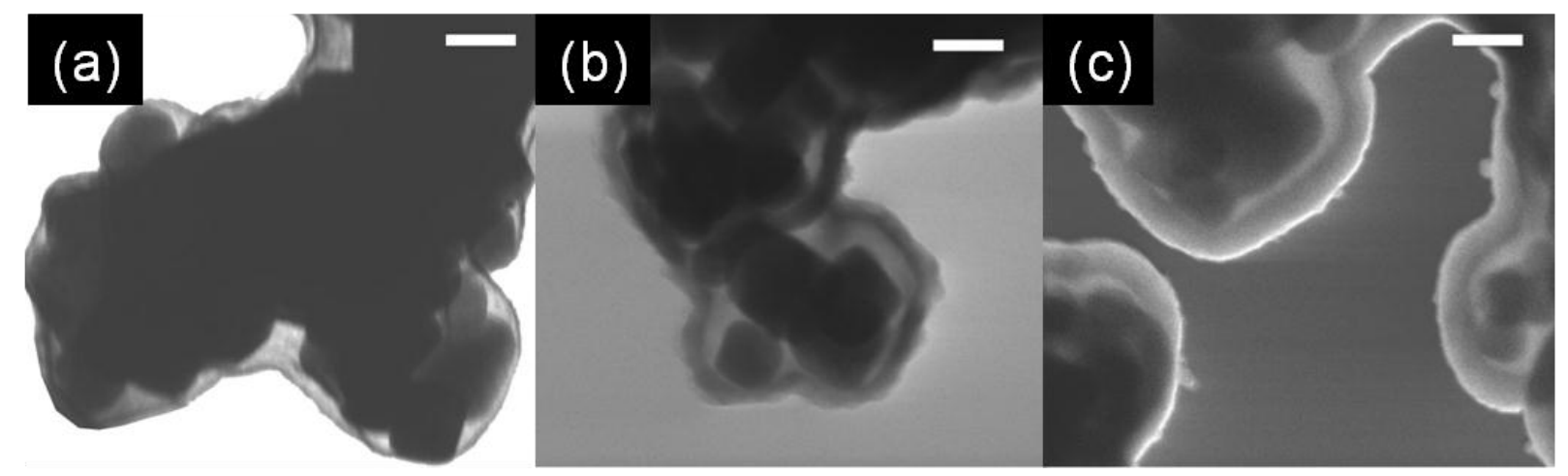

Fig. 2 SEM images taken in transmission mode of (a) $\mathrm{SiO}_{2}(0.5) /$ void/TiO 2 , (b) $\mathrm{SiO}_{2}(1.5) /$ void/TiO 2 and (c) $\mathrm{SiO}_{2}(3.0) /$ void/TiO $/$. Scale bars correspond to $100 \mathrm{~nm}$. 


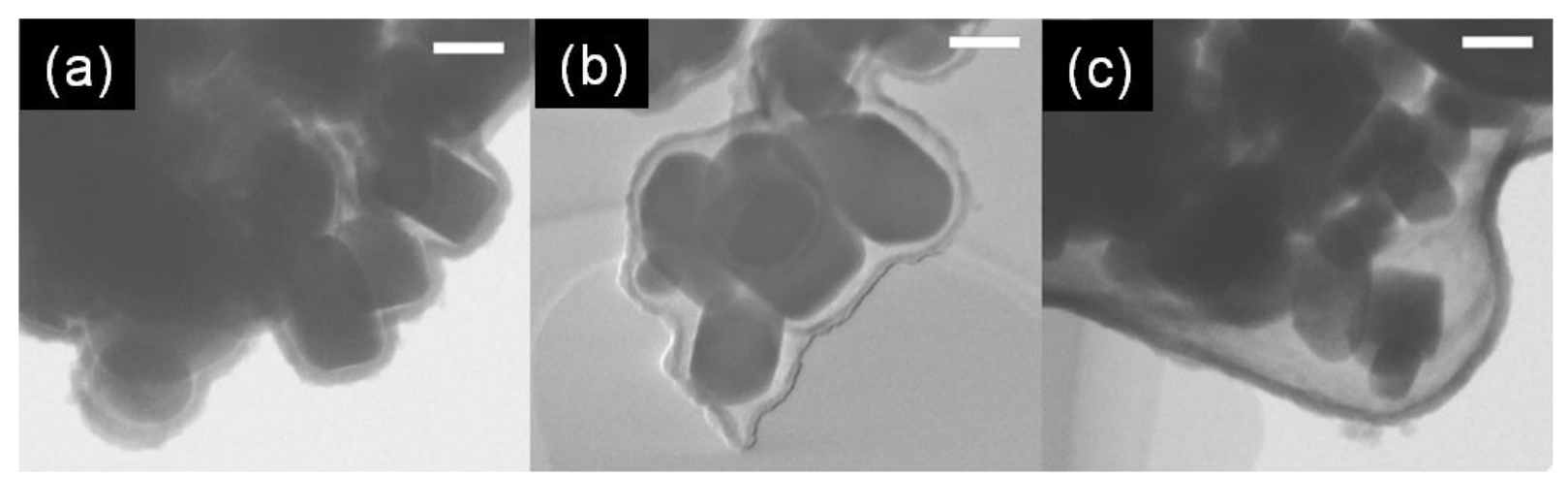

Fig.3 SEM images taken in transmission mode of $\mathrm{SiO}_{2}(1.5) /$ void/TiO 2 prepared with different glucose concentrations of (a) $0.25 \mathrm{~mol} \mathrm{dm}^{-3}$, (b) $0.5 \mathrm{~mol} \mathrm{dm}^{-3}$ and (c) $2.0 \mathrm{~mol}$ $\mathrm{dm}^{-3}$. Scale bars correspond to $100 \mathrm{~nm}$. 


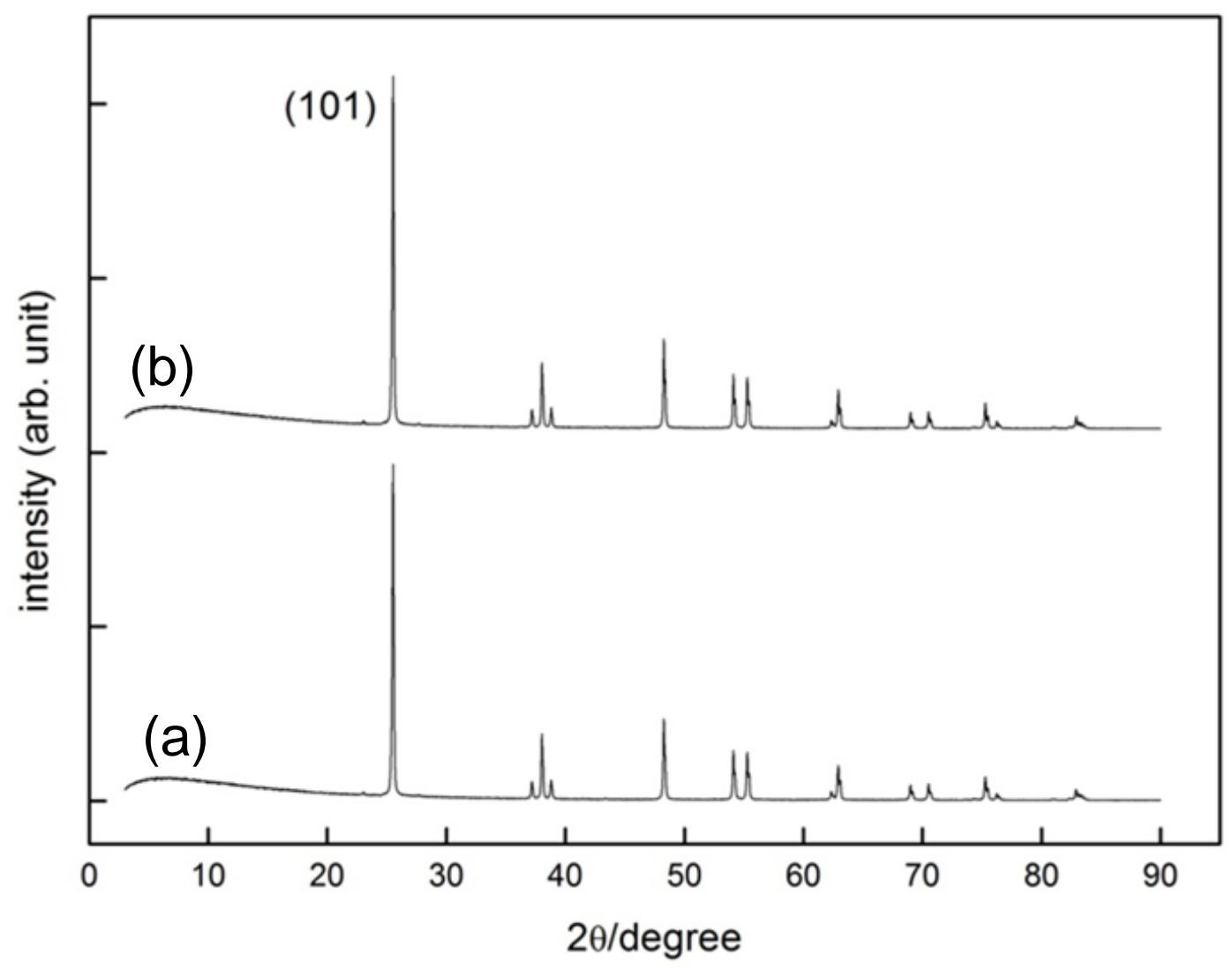

Fig. 4 XRD patterns of (a) $\mathrm{TiO}_{2}(\mathrm{ST}-41)$ and (b) $\mathrm{SiO}_{2}(0.5) /$ void/TiO 2 . 


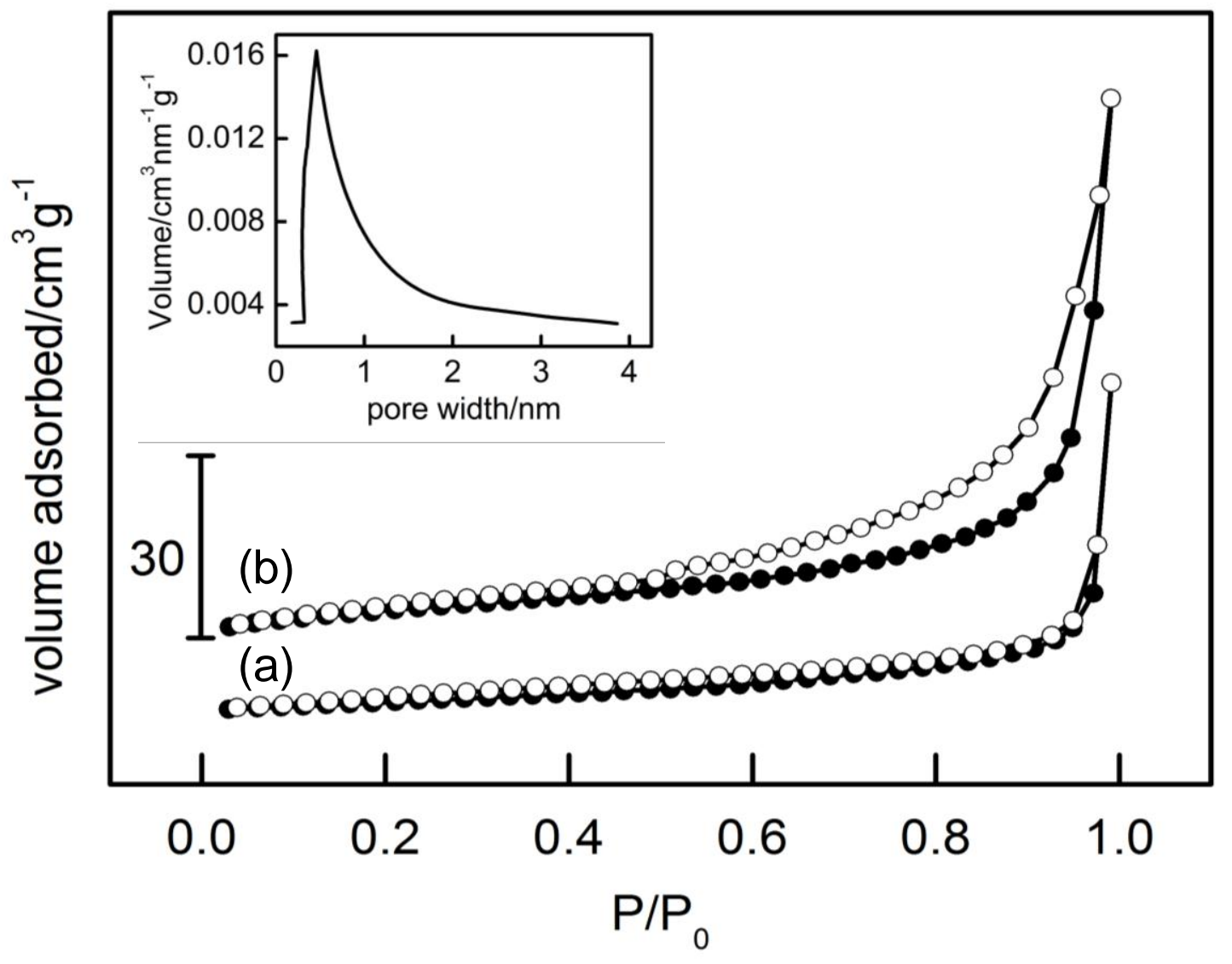

Fig. $5 \mathrm{~N}_{2}$ adsorption-desorption isotherms of (a) $\mathrm{TiO}_{2} \quad$ (ST-41) and (b) $\mathrm{SiO}_{2} /$ void $/ \mathrm{TiO}_{2}$. Filled and open circles denote adsorption and desorption branches, respectively. 


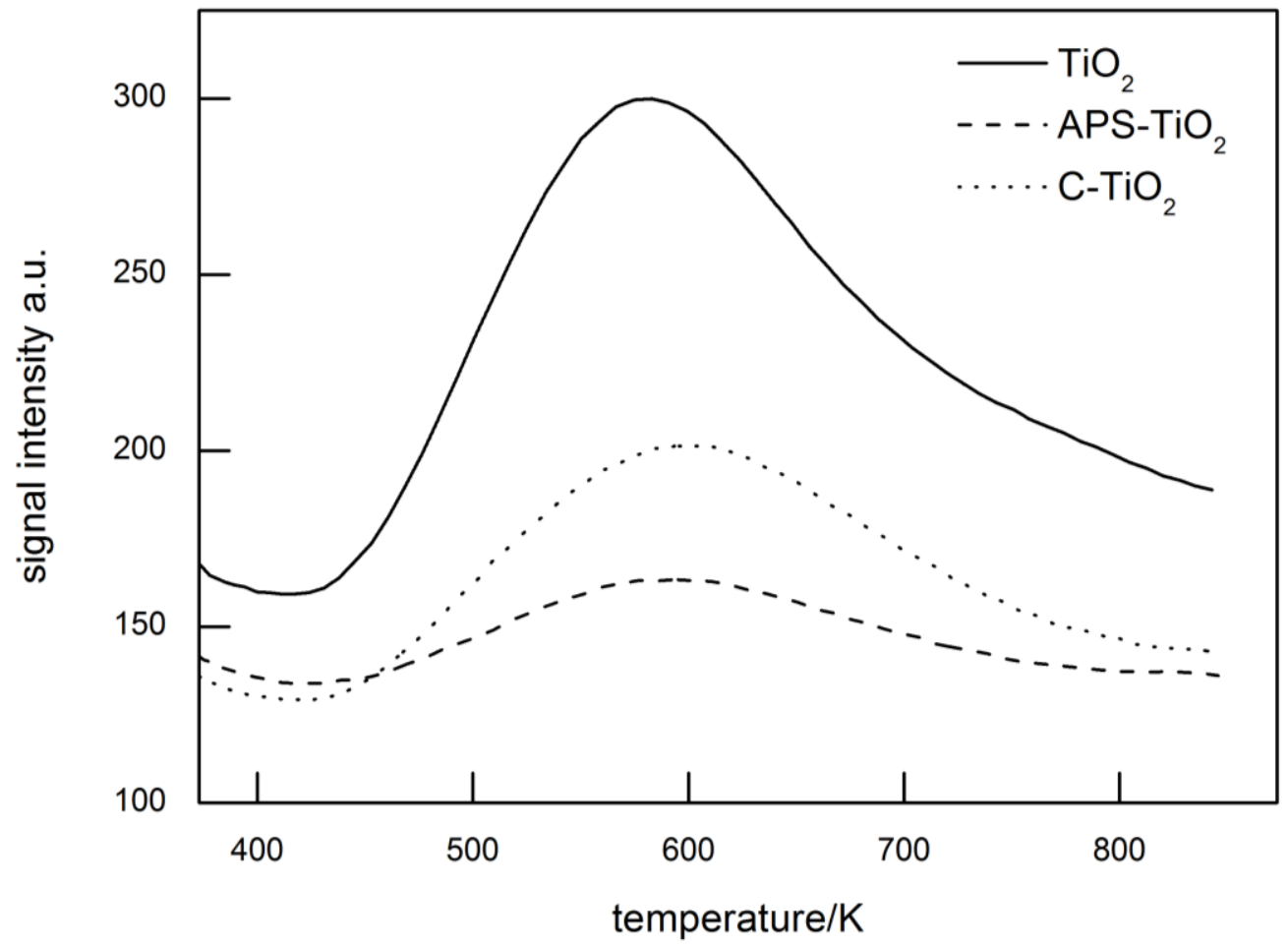

Fig. $6 \mathrm{NH}_{3}-\mathrm{TPD}$ patterns for $\mathrm{TiO}_{2}$, APS-TiO 2 and $\mathrm{C}-\mathrm{TiO}_{2}$. 


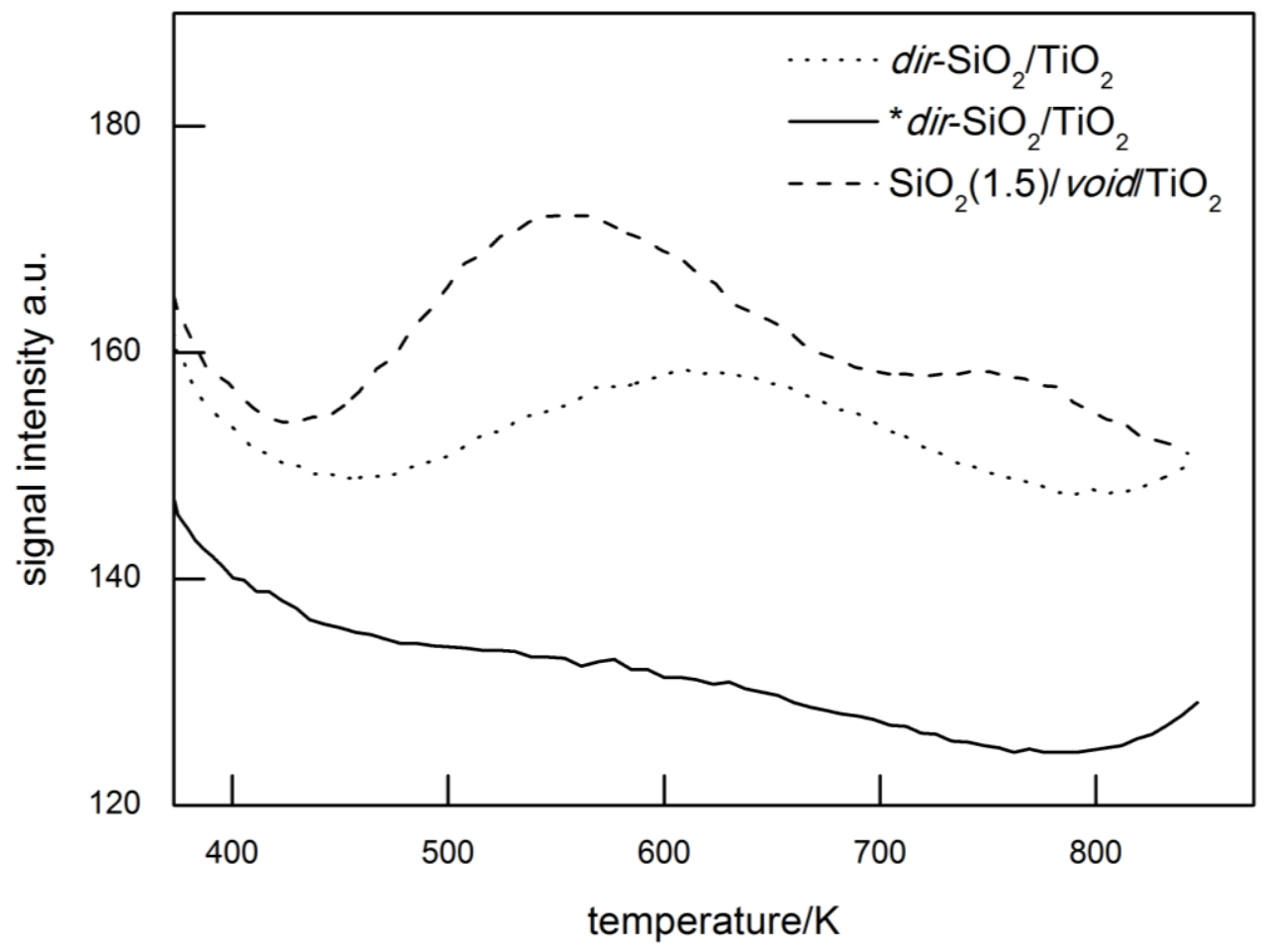

Fig. $7 \mathrm{NH}_{3}$-TPD patterns for $\operatorname{dir}-\mathrm{SiO}_{2} / \mathrm{TiO}_{2}, \quad \operatorname{dir}-\mathrm{SiO}_{2} / \mathrm{TiO}_{2}$ heated at $973 \mathrm{~K}$ $\left(*\right.$ dir $\left.-\mathrm{SiO}_{2} / \mathrm{TiO}_{2}\right)$ and $\mathrm{SiO}_{2}(1.5) /$ void/ $/ \mathrm{TiO}_{2}$. 


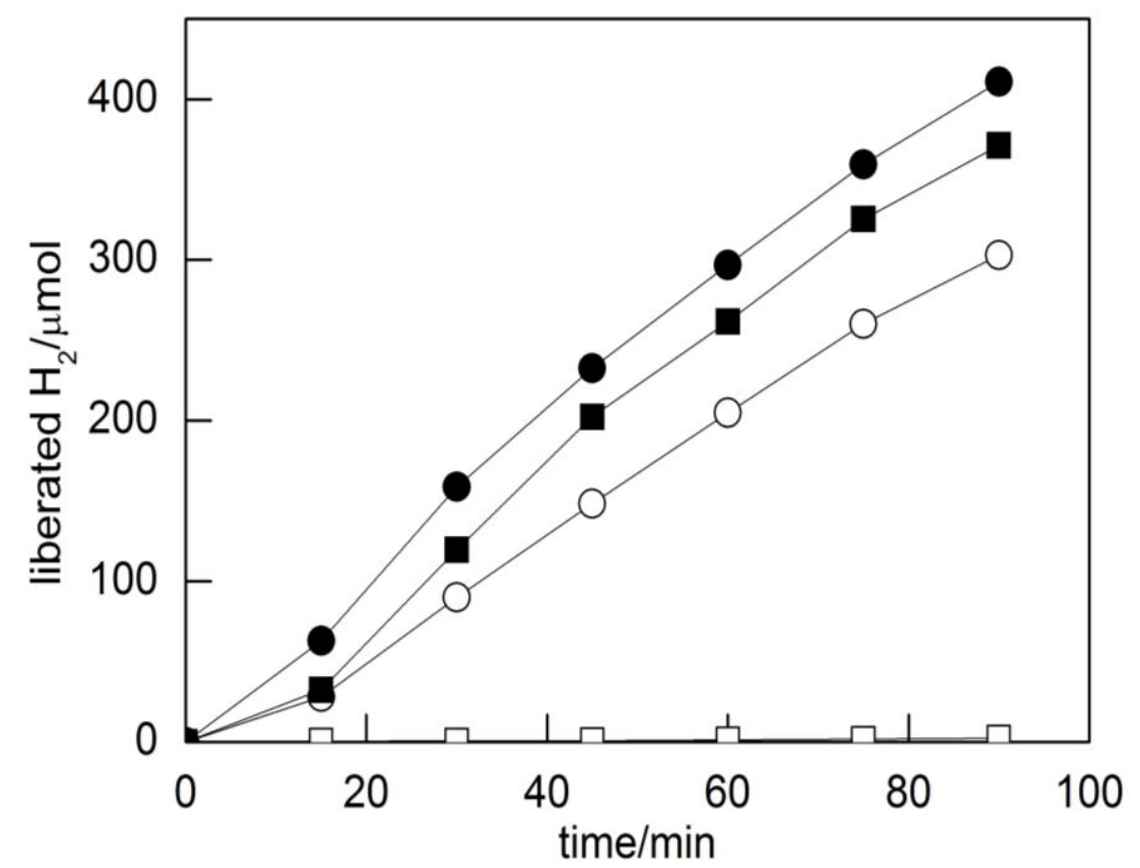

Fig. 8 Time course curves of liberated $\mathrm{H}_{2}$ on $\mathrm{TiO}_{2}$ (filled circles), $\mathrm{SiO}_{2} /$ void/TiO $/$ (filled squares), mec- $\mathrm{SiO}_{2}+\mathrm{TiO}_{2}$ (open circles) and dir- $\mathrm{SiO}_{2} / \mathrm{TiO}_{2}$ (open squares) from an aqueous methanol solution in the presence of $\mathrm{H}_{2} \mathrm{PtCl}_{6}$. 


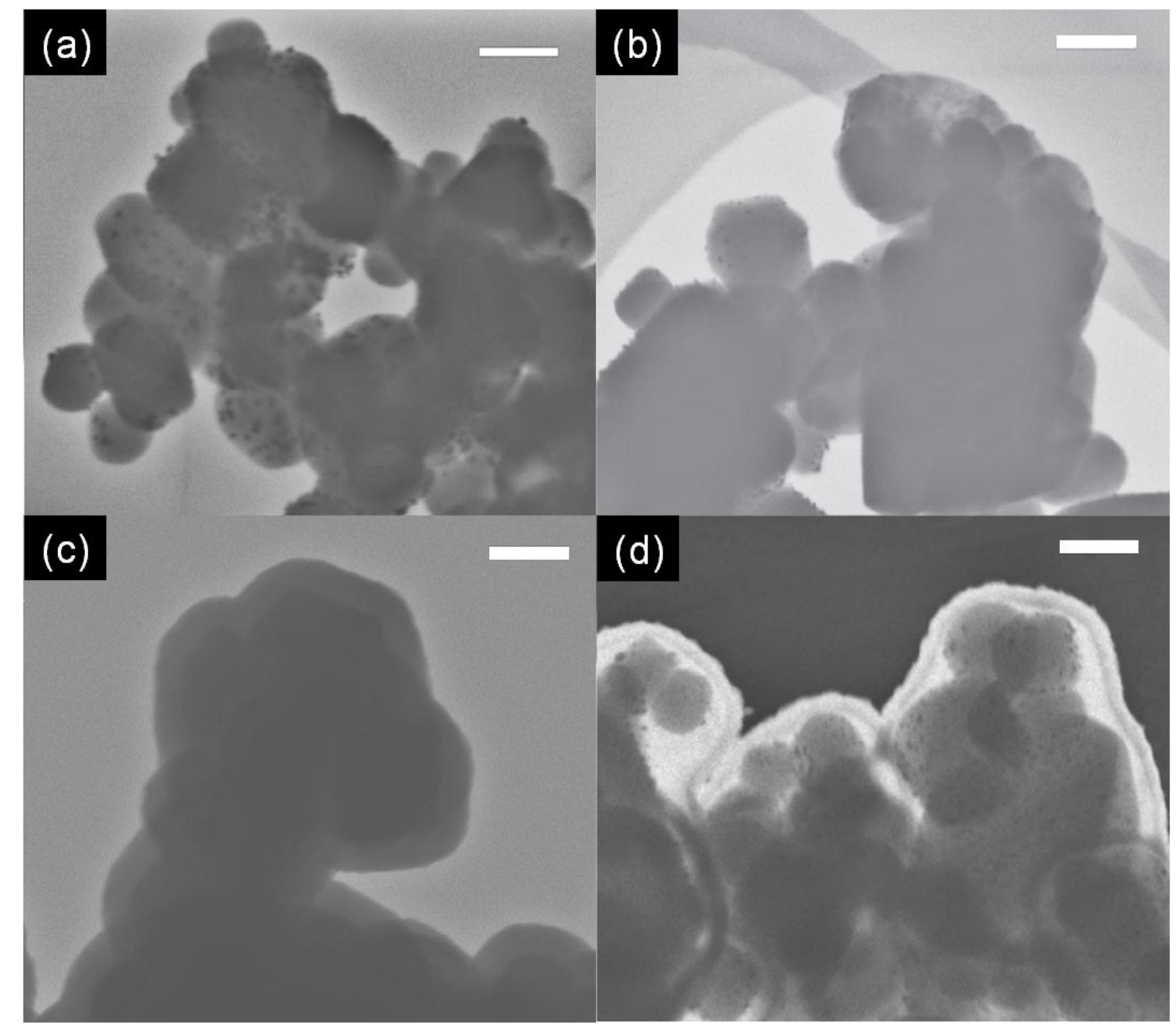

Fig. 9 SEM images taken in transmission mode of platinized (a) $\mathrm{TiO}_{2}$, (b) $m e c-\mathrm{SiO}_{2}+\mathrm{TiO}_{2}$, (c) dir- $\mathrm{SiO}_{2} / \mathrm{TiO}_{2}$ and (d) $\mathrm{SiO}_{2}(0.5) /$ void/TiO 2 . Scale bars correspond to $100 \mathrm{~nm}$. 